Efeito tigela em linhas de produção: novas evidências computacionais

\author{
Pedro Belin Castellucci
}





\title{
Efeito tigela em linhas de produção: novas evidências computacionais
}

\author{
Pedro Belin Castellucci
}

Orientador: Prof. Dr. Alysson M. Costa

Dissertação apresentada ao Instituto de Ciências Matemáticas e de Computação - ICMC-USP, como parte dos requisitos para obtenção do título de Mestre em Ciências - Ciências de Computação e Matemática Computacional. VERSÃO REVISADA 
Ficha catalográfica elaborada pela Biblioteca Prof. Achille Bassi e Seção Técnica de Informática, ICMC/USP, com os dados fornecidos pelo(a) autor(a)

C348e $\begin{aligned} & \text { Castellucci, Pedro Belin } \\ & \text { Efeito tigela em linhas de produção: novas } \\ & \text { evidências computacionais / Pedro Belin } \\ & \text { Castellucci; orientador Alysson M. Costa. -- São } \\ & \text { Carlos, } 2014 \text {. } \\ & 70 \text { p. } \\ & \text { Dissertação (Mestrado - Programa de Pós-Graduação } \\ & \text { em Ciências de Computaço e Matemática } \\ & \text { Computacional) -- Instituto de Ciências Matemáticas } \\ & \text { e de Computação, Universidade de São Paulo, 2014. } \\ & \text { l. linhas de produção. 2. efeito Tigela. 3. } \\ & \text { linhas não-ritmadas. 4. programação matemática. 5. } \\ & \text { simulação. I. Costa, Alysson M., orient. II. Título. }\end{aligned}$




\section{Agradecimentos}

Comecei o mestrado devido a uma compatibilidade geográfica e uma atitude de "por que não?". Mas o tempo passou e o que era passatempo virou atividade principal. E hoje, talvez pela primeira vez, eu sei o que quero fazer nos próximos anos. Algumas pessoas influenciaram nessa transformação, provavelmente sem saber, e fica aqui o meu agradecimento a elas.

À minha família, mãe, pai, Renato, Ana e Júlia, que sempre esteve por perto.

Aos meus amigos, Angelo, Vinícius, Maria Fernanda e Vanessa, que sempre me lembram que olhar em volta é tão importante quanto olhar pra si mesmo.

Ao meu orientador, Alysson, com quem sempre aprendi muito e que sempre me atendeu com paciência e atenção, mesmo a meio mundo de distância. E com quem ainda espero trabalhar muitas outras vezes. 



\section{Resumo}

Castellucci, Pedro Efeito Tigela em linhas de produção: novas evidências computacionais. 70 p. Dissertação de mestrado - Instituto de Ciências Matemáticas e de Computação, Universidade de São Paulo, Outubro de 2014.

Linhas de produção são sistemas fabris para produção em larga escala, com grande importância no sistema industrial atual. Como se trata de um sistema já consolidado, é natural que existam métricas de desempenho e estratégias para otimização de eficiência para as diversas configurações de linhas de produção existentes. Este trabalho se concentra em linhas seriais não-ritmadas e estocásticas. Em particular, o interesse é no efeito de se desbalancear adequadamente uma linha de produção para melhorar sua produtividade, o que é denominado na literatura de fenômeno Tigela (Bowl phenomenon). Uma revisão da literatura mostrou que esse fenômeno já foi estudado em diferentes cenários: linhas com e sem buffers, diversos perfis de carga ao longo da linha e diferentes distribuições probabilísticas regendo os tempos de execução das tarefas. Contudo, nenhum dos estudos considerou a indivisibilidade das tarefas, isto é, o fato de que cada tarefa deve ser executada em uma única estação. Essa é a principal lacuna explorada neste estudo. Para isso, são utilizadas instâncias recentemente propostas do Problema Simples de Balanceamento de Linhas de Produção (SALBP, na sigla em inglês) e instâncias do Problema de Designação de Trabalhadores e Balanceamento de Linhas de Produção (ALWABP), que são solucionadas a partir de modelos de programação inteira mista que induzem soluções de acordo com o efeito Tigela. Essas soluções são utilizadas em um modelo de simulação estocástico, também apresentado neste trabalho. Em linhas gerais, os resultados mostram que as soluções do SALBP e ALWABP obtidas podem se beneficiar do efeito Tigela. Além disso, a variedade das instâncias utilizadas nos experimentos argumentam em favor de uma maior capacidade de generalização dos resultados para casos práticos se comparados aos casos simplificados previamente discutidos na literatura.

Palavras-chave: linhas de produção; efeito Tigela; linhas não-ritmadas. 



\section{Abstract}

Castellucci, Pedro Bowl phenomenon in assembly lines: new computational evidence. 70 p. Master Thesis - Institute of Mathematical Science and Computation, University of São Paulo, October of 2014.

Assembly lines are large-scale production systems with great value in modern industrial systems. Perfomance measures and strategies have been proposed in order to evaluate and improve the efficiency of numerous assembly line configurations. This dissertation focuses on serial unpaced (stochastic) assembly lines. In particular, the interest of this study is in the effect of deliberately unbalacing the line in a specific manner in order to enhance its performance, a strategy that exploits the so-called Bowl phenomenon. The literature has studied this phenomenon in different scenarios: buffered and unbuffered lines, different workload profiles along the line and different probabilistic task time distributions. However, none of the identified studies considers task indivisibility, an intrisic characteristic of real-world assembly line balancing problems, namely, each task has to be executed in a single station. This is the main gap explored in this study. Thereunto, we use recently proposed instances for the Simple Assembly Line Balancing Problem (SALBP) and some Assembly Line Worker Assignment and Balancing Problem (ALWABP) instances, which are solved using mixed integer programming models capable of inducing bowl workload profiles. These solutions are used as input in a stochastic simulation model, also presented in this study. Overall, the results show that SALBP and ALWABP solutions may benefit from the Bowl phenomenon. Furthermore, the variety of the instances considered in the experiments allows for a better generalization of the results to real-world scenarios if compared to the simplified cases previously shown in the literature.

Keywords: assembly lines; Bowl phenomenon; unpaced lines. 



\section{Lista de ilustrações}

Figura 1 Exemplo de balanceamento com tempo de ciclo de oito unidades. O conjunto de tarefas $N=\{1,2,3,4,5,6,7,8,9\}$ é particionado em $S_{1}=$ $\{1,4\}, S_{2}=\{2,3,7\}, S_{3}=\{5,6\}, S_{4}=\{8\}$ e $S_{5}=\{9\}$, que correspondem a um balanceamento. Os valores ao lado dos nós indicam os tempos de execução das tarefas correspondentes. . . . . . . . . . . . . . 22

Figura 2 Exemplo de simulação da velocidade (eixo vertical) de um automóvel ao longo do tempo (eixo horizontal). Quanto menor o passo de tempo, $\Delta t$, maior a precisão da simulação e maior o esforço computacional necessário para realizar toda a simulação. . . . . . . . . . . . . . . 28

Figura 3 Exemplo no qual o uso de discretização temporal pode não ser adequado. As estrelas marcam momentos em que o botão foi pressionado. Note que pode ser complicado definir $\Delta t$ de forma a detectar eventos instantâneos. Uma alternativa, então, seria utilizar a técnica de eventos discretos para modelar a passagem do tempo. . . . . . . . . . . . . 28

Figura 4 Abordagem de três fases para simulação de eventos discretos: as fases A, B e C se repetem ciclicamente até que o critério de parada da simulação seja atingido. Figura adaptada de (ROBINSON, 2004). . . . . 29

Figura 5 Exemplo de aplicação do método de Monte Carlo. A área do quarto de circunferência de raio unitário é $\frac{\pi}{4}$. Conforme são gerados pontos dentro do quadrado unitário, a razão entre o número de pontos dentro da circunferência (marcados com "x") e fora dela (mas dentro do quadrado - marcados com "o") é uma aproximação para o valor de $\frac{\pi}{4}$ e, quanto maior o número de pontos gerados, mais precisa é a aproximação. . . . 31 
Figura 6 A curva Normal ilustra o conhecimento do professor sobre os erros ortográficos de alunos de uma determinada faixa etária $(\mu=10$ e $\sigma=2)$. O aluno a ser classificado possui um desempenho médio equivalente a $\mu-2 \sigma=6$, significando que apenas $2,3 \%$ da população considerada possuem um desempenho melhor (menos erros) que o do aluno no quesito ortografia. As porcentagens na figura indicam a área da faixa delimitada pelas linhas tracejadas em relação a área total da curva. . . 33

Figura 7 Exemplo de alocação característica do efeito Tigela: as estações centrais menos carregadas que as estações das extremidades. . . . . . . . . 36

Figura 8 Esquema geral da solução utilizada para determinar a produtividade de linhas estocásticas a partir de soluções determinísticas de um modelo de programação inteira mista. O MIP recebe como entrada uma instância, isto é, o grafo de precedências entre as tarefas, o número de estações de trabalho e o tempo de execução das tarefas (no caso do ALWABP, segundo o trabalhador que as executam). Esse modelo fornece um balanceamento que, em conjunto com a hipótese de que os tempos de execução das tarefas seguem uma distribuição Normal, é utilizado como entrada para um modelo de simulação. Por fim, após a simulação, tem-se o tempo necessário para a produção de uma quantidade prédeterminada de itens. . . . . . . . . . . . . . . . . 4 41

Figura 9 Balanceamentos induzidos para diferentes valores de $\alpha_{1}>0$ e $\beta \in(0,1]$. 43

Figura 10 Máquina de estados simplificada para as estações de trabalho. Quando uma estação está realizando algum trabalho seu estado é OCUPADA; no estado BLOQUEADA, ela está esperando a estação seguinte finalizar seu trabalho; e no estado LIVRE a estação está esperando a anterior enviar algum produto. . . . . . . . . . . . . . . . 45

Figura 11 Fluxograma de uma simulação. A simulação avança até o próximo evento agendado e tenta processar os eventos necessários. Se nenhum deles pode ser realizado, o tempo é novamente avançado até que pelo menos uma estação esteja livre. A simulação termina quando o número de produtos especificado é atingido. . . . . . . . . . . . 4 46

Figura 12 Esquema representando os cenários dos experimentos realizados. Os experimentos principais investigam o SALBP e o ALWABP e, para cada um, o efeito Tigela relativo à média, $\mu$, e ao desvio-padrão, $\sigma$. Os experimentos complementares utilizam apenas o SALBP e o efeito em relação à média para geração dos resultados desejados. . . . . . . . . . . . 48 
Figura 13 Análise de regime permanente. Pode-se notar, pelo gráfico, que antes da produção do vigésimo item a linha já pode ser considerada em regime permanente. Neste trabalho, escolheu-se o limite de 50 unidades, de forma a garantir a operação em regime permanente para todas as instâncias consideradas. Também, nos casos considerados o regime permanente é atingido de forma relativamente rápida, pois não há buffers entre as estações. . . . . . . . . . . . . . . . . . . . . . 49

Figura 14 A linha tracejada mostra o que seria uma alocação tigela ideal e os quadrilatéros representam as tarefas indivisíveis. Para este exemplo, as estações 2 e 4 têm a carga "ideal" e as demais estações têm cargas menores. Note que essa situação não viola as restrições do modelo modificado para o SALBP. . . . . . . . . . . . . . . . . . . . 51

Figura 15 Diagrama de classes simplificado do simulador, mostrando a relação entre as classes: Workstation, AssemblyLine, Simulation e Task. . . . . 68 



\section{Lista de tabelas}

Tabela 1 Algumas características de trabalhos na literatura acerca do efeito Tigela. A coluna Análise se refere à técnica utilizada para estudar o efeito: analítica ou simulação. A coluna Estações se refere ao número máximo de estações utilizado na análise. A coluna Distribuição identifica a(s) distribuição(ões) de probabilidade(s) considerada(s) e, por fim, a coluna Efeito Tigela diferencia estudos com conclusões a favor ou contra o efeito Tigela. (O trabalho (KALA; HITCHINGS, 1973), não especifica a distribuição com viés positivo que foi utilizada, por isso a expressão "viés positivo" se encontra na célula correspondente). Nesta tabela foram incluídos apenas trabalhos que fornecem argumentos, mesmo que implícitos, a favor ou contra o efeito Tigela como apresentado por HILLIER; BOLING $(1966) \ldots \ldots \ldots$. . . . . . . . . . . . 39

Tabela 2 Resultados de desbalanceamento da média para instâncias SALBP agrupados por número de estações. . . . . . . . . . . . . . . . . . . 53

Tabela 3 Resultados de desbalanceamento da média para instâncias SALBP agrupados por estrutura do grafo de precedências e distribuição do tempo de execução das tarefas. . . . . . . . . . . . . . . . . . . 54

Tabela 4 Resultados de desbalanceamento da média para instâncias SALBP combinando número de estações com estrutura do grafo de precedências ou distribuição do tempo de execução das tarefas. . . . . . . . . . . 55

Tabela 5 Resultados de desbalanceamento de desvio-padrão para instâncias SALBP agrupados por número de estações. . . . . . . . . . . . . . . . . . . 56

Tabela 6 Resultados de desbalanceamento de desvio-padrão para instâncias SALBP agrupados por estrutura do grafo de precedências e distribuição do tempo de execução das tarefas. . . . . . . . . . . . . . . . . . . . 56 
Tabela 7 Resultados de desbalanceamento de desvio-padrão para instâncias SALBP combinando número de estações com estrutura do grafo de precedências ou distribuição do tempo de execução das tarefas. . . . . . . . . . . 57

Tabela 8 Resultados para desbalanceamento de média e desvio-padrão para instâncias ALWABP agrupados por variabilidade (baixa ou alta) dos tempos de execução das tarefas. . . . . . . . . . . . . . . . . 58 58

Tabela 9 Resultados para desbalanceamento de média e desvio-padrão para instâncias ALWABP agrupados por incompatibilidade (baixa ou alta) das tarefas em relação aos trabalhadores. . . . . . . . . . . . . . . . 58

Tabela 10 Comparação entre os métodos de geração de alocações com o perfil de tigela. Cada célula contém o número de instâncias que obtiveram o melhor desempenho se comparadas com os outros métodos. Os experimentos foram realizados considerando dois coeficientes de variação. 58 


\section{Sumário}

1 Introdução 17

1.1 Objetivos da pesquisa . . . . . . . . . . . . . . . . . . 18

2 Contexto teórico $\quad 21$

2.1 Balanceamento de linhas de produção . . . . . . . . . . . . . . . . . 21

2.1 .1 SALBP . . . . . . . . . . . . . . . . 22

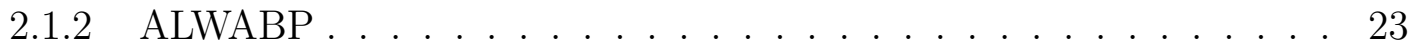

2.2 Simulação . . . . . . . . . . . . . . . . . . . . . . . 25

2.2.1 Modelando o avanço do tempo . . . . . . . . . . . . . . 27

2.3 Outros conceitos . . . . . . . . . . . . . . . . . . . 30

2.3.1 Métodos de Monte Carlo . . . . . . . . . . . . . . . . . . . . 30

2.3 .2 Simulação-otimização . . . . . . . . . . . . . . . . . . . 31

2.3.3 Testes de hipótese . . . . . . . . . . . . . . . . . . . . . 32

$3 \quad$ Revisão da literatura $\quad 35$

4 Metodologia de desenvolvimento $\quad 41$

4.1 Geração de soluções tigela . . . . . . . . . . . . . . . . . . . . . . . . . . 41

4.2 Modelo de simulação . . . . . . . . . . . . . . . . . . . . . . . . . . . 44

$\begin{array}{lll}5 & \text { Experimentos computacionais } & 47\end{array}$

5.1 Planejamento de experimentos . . . . . . . . . . . . . . . . . 47

5.1.1 Experimentos principais . . . . . . . . . . . . . . 48

5.1.2 Experimentos complementares . . . . . . . . . . . . 50

5.2 Resultados . . . . . . . . . . . . . . . . . . . . . 52

6 Conclusões e trabalhos futuros $\quad 59$

$\begin{array}{ll}\text { Referências } & 61\end{array}$ 


\section{Introdução}

Linhas de produção são sistemas fabris especialmente úteis na fabricação, em larga escala, de itens padronizados (SCHOLL, 1999). A ideia básica desses sistemas está em dividir o processo de fabricação em pequenas tarefas a serem executadas em sequência por diversos trabalhadores em áreas denominadas estações de trabalho. Assim, no processo de fabricação de um produto, ele deve ser transportado de uma estação para a outra. Em cada estação, parte das tarefas necessárias é realizada e, ao final, tem-se o produto completo.

As linhas de produção começaram a ganhar importância na década de 1920 em sistemas de produção em massa, que permitiram uma produção eficiente a um custo relativamente baixo (RAPP, 2009). Desde então, os requisitos de produção mudaram bastante e as linhas de produção foram adaptadas para acompanhar essas mudanças. Máquinas com propósitos variados permitem às linhas produzirem modelos diferentes, tornando o sistema adequado, também, a produções de menor volume e permitindo estratégias produtivas como a customização em massa. Dessa forma, pode-se notar que o planejamento e implementação das linhas de produção devem continuar tendo relevância prática em um futuro próximo (BOYSEN; FLIEDNER; SCHOLL, 2007).

Projetar uma linha de produção envolve uma série de decisões. Entre elas: a quantidade de estações de trabalho, o tipo de fluxo de produtos desejado, a quantidade e variedade dos produtos a serem fabricados, a disposição espacial das estações de trabalho, a existência de buffers entre as estações, quais tarefas serão realizadas em cada estação de trabalho e qual trabalhador será alocado a cada estação. Essas possíveis escolhas originam linhas de tipos e problemas decisórios diferentes.

Uma forma de se classificar as linhas de produção é dividi-las em linhas ritmadas e não-ritmadas. Linhas ritmadas possuem tempo de ciclo, isto é, cada estação tem um tempo máximo (tempo de ciclo) para realizar todas as tarefas que estão alocadas a ela. Após o término desse tempo, o produto é transportado para a estação seguinte e um novo produto a ser trabalhado é recebido. Em linhas não-ritmadas, não existe tempo de ciclo e uma estação, ao terminar seu trabalho, verifica se é possível enviar o produto à estação 
seguinte; se não for possível, ela aguarda até que o seja. Por outro lado, uma estação pode enviar o produto à estação seguinte e não receber um novo da estação precedente implicando, também, em tempo ocioso para a estação. Em geral, na literatura, assume-se que a última estação sempre pode enviar o produto para frente na linha e a primeira sempre tem um produto disponível para iniciar um novo trabalho.

Outra classificação possível é dividir as linhas em determinísticas ou estocásticas. Em linhas determinísticas, os tempos de execução das tarefas são determinísticos, isto é, uma tarefa sempre demora um tempo determinado para ser concluída e, em linhas estocásticas, esse tempo é regido por uma distribuição probabilística. Em geral, linhas completamente automatizadas e mecanizadas são linhas que podem ser bem descritas como linhas determinísticas, enquanto que linhas que envolvem ação humana para realização das tarefas são linhas de produção estocásticas. Neste trabalho, o termo "não-ritmada" está sendo utilizado como sinônimo de "estocástica", isto é, linhas não-ritmadas são linhas em que o tempo para realização das tarefas segue alguma distribuição probabilística.

Usualmente, ao se tentar otimizar uma linha de produção determinística, busca-se por uma alocação de tarefas que minimize o tempo de ciclo, o que implica em uma alocação de forma que todas as estações fiquem com a mesma carga de trabalho. O tempo de ciclo mínimo leva a uma taxa produtiva máxima para linhas de produção determinísticas. No entanto, para linhas estocásticas, nas quais os tempos das tarefas são regidos por distribuições probabilísticas específicas, resultados empíricos indicam que um aumento na taxa produtiva pode ser obtido ao se desbalancear apropriadamente a carga das estações de trabalho, efeito conhecido como fenômeno Tigela ou Bowl phenomenon (HILLIER; BOLING, 1966).

O fenômeno Tigela é o alvo de estudo deste trabalho. Especificamente, o fenômeno é analisado no contexto de dois problemas de balanceamento de linhas do produção: o Simple Assembly Line Balancing Problem (SALBP) e o Assembly Line Worker Assignment Balancing Problem (ALWABP). O estudo é feito com o objetivo de investigar algumas lacunas identificadas na literatura acerca do efeito Tigela.

\subsection{Objetivos da pesquisa}

Os objetivos da pesquisa são apresentados aqui, no início do texto, para que se possa têlos em mente ao longo da leitura. O objetivo geral do trabalho é, como já foi mencionado, estudar o efeito Tigela. Para que seja possível avaliar os resultados obtidos, foi definido um objetivo específico que é responder a algumas perguntas acerca do efeito Tigela. Elas são apresentadas a seguir:

1. O fenômeno Tigela pode ter aplicações práticas ou seus efeitos são observáveis apenas na teoria? 
2. Existe alguma característica dos problemas de balanceamento de linhas de produção que favorece o aparecimento do efeito Tigela?

3. O problema de balanceamento de linhas de produção e designação de trabalhadores pode se beneficiar do efeito Tigela?

Essas questões foram definidas a partir de uma investigação da literatura, apresentada no Capítulo 3. A questão 1 está relacionada ao fato de nenhum dos estudos investigados utilizar instâncias representativas para o SALBP. Na verdade, os estudos prévios utilizam instâncias "artificiais" nas quais não há a característica de indivisibilidade das tarefas, isto é, sempre existe uma tarefa com duração adequada para preencher a carga desejada para qualquer estação, o que, em situações práticas, é pouco provável. Considerando um conjunto de instâncias recentemente proposto na literatura, contendo problemas com uma gama diversa de características (OTTO; OTTO; SCHOLL, 2013), definiu-se a questão 2 que, caso respondida afirmativamente, permitirá a obtenção de indicativos de que a instância do problema a ser resolvida terá potencial para se beneficiar do efeito Tigela. Por fim, além de se estudar o efeito Tigela no contexto do SALBP, também se tem por objetivo investigar o potencial da aplicação deste fenômeno no contexto do ALWABP.

Para essa investigação são propostos modelos determinísticos de programação inteira mista (para o SALBP e o ALWABP) capazes de induzir a geração de alocações adequadas para o efeito Tigela e que consideram a indivisibilidade das tarefas. Considerando a indivisibilidade, não é possível distribuir a carga de trabalho arbitrariamente pela linha de produção, de certa forma pode-se entender que a carga total de trabalho a ser realizada é constituída por blocos de carga e um bloco precisa, necessariamente, estar todo em uma única estação. Além disso, são desenvolvidas estratégias para a exploração das alocações geradas pelos modelos propostos com o objetivo de avaliar a ocorrência do efeito Tigela.

Essas soluções, com tarefas indivisíveis, são utilizadas por um modelo de simulação estocástico, também desenvolvido neste trabalho, no qual os tempos de processamento, apenas, são considerados variáveis aleatórias. No Capítulo 2, a seguir, é apresentada uma revisão dos conceitos relacionados ao SALBP, ao ALWABP e às técnicas de simulação de eventos. No Capítulo 3, são apresentados trabalhos relacionados ao efeito Tigela enquanto que, o Capítulo 4 expõe os modelos de programação inteira mista para geração de soluções no padrão Tigela e o modelo de simulação propostos. A definição dos experimentos e os respectivos resultados estão discutidos no Capítulo 5. Por fim, no Capítulo 6, são tecidas conclusões e enumeradas algumas possibilidades de trabalhos futuros. 


\section{Contexto teórico}

\subsection{Balanceamento de linhas de produção}

Três definições são importantes para o entendimento de problemas de balanceamento de linhas de produção e, em especial, dos dois problemas com os quais este trabalho está relacionado.

Definição 1 (grafo de precedências): um grafo de precedências $G=(N, A, t)$ é um dígrafo não-cíclico com o conjunto $N=\{1, \ldots, n\}$ de $n$ vértices (nós) e um conjunto $A=\{(i, j) \mid i, j \in N\}$ de arcos (arestas). Nós denotam tarefas a serem executadas e arcos representam precedências diretas entre as tarefas, isto é, uma tarefa $i \in N$ precisa ser executada antes de uma tarefa $j \in N$ se a aresta $(i, j) \in A$. Uma tarefa $i$ é dita predecessora de $j$ se ela precisa ser executada antes de $j$, enquanto que $j$ é dita sucessora de $i$. A relação é direta quando $(i, j) \in A$. O conjunto de sucessores diretos de $i$ é denotado por $F_{i} \subset N$. Por simplicidade e sem perda de generalidade, assume-se que o grafo de precedências é topologicamente ordenado, isto é, para qualquer arco $(i, j)$ tem-se $i<j$. Além disso, a notação $i \lessdot j$ é utilizada para indicar que $j \in F_{i}$. O peso de um nó, $t_{i}$, representa o tempo necessário para realizar a tarefa $i$.

Definição 2 (estação de trabalho): uma estação de trabalho é um elemento da linha de produção. Cada tarefa tem que estar alocada a uma estação para que sua realização seja possível. Também, uma tarefa é alocada à exatamente uma estação de trabalho.

Definição 3 (balanceamento da linha): uma partição do conjunto $N=\{1, \ldots, n\}$ de todas as tarefas em $m$ subconjuntos disjuntos $S_{k}, k=1, \ldots, m$, é chamada de alocação de tarefas se $i \in S_{h}$ e $j \in S_{k} \operatorname{com} h \leq k$ para $(i, j) \in A$; note que $S=\cup_{i=1}^{m} S_{i}$ é o conjunto das estações de trabalho. De outra forma, cada tarefa é alocada a exatamente uma das $m$ estações e as restrições de ordem entre as tarefas, denotadas pelo grafo de precedências, são respeitadas. Uma alocação de tarefas é dita factível se, para cada estação, a soma de todos os tempos das tarefas alocadas a ela não ultrapassa o tempo de ciclo definido para a linha de produção. Uma alocação factível é denominada balanceamento da linha. A 
Figura 1 apresenta um exemplo de grafo de precedências com um possível balanceamento considerando um tempo de ciclo de oito unidades. O restante dessa seção apresentará os dois problemas de balanceamento de linhas de produção que estão relacionados com este trabalho: o SALBP e o ALWABP.

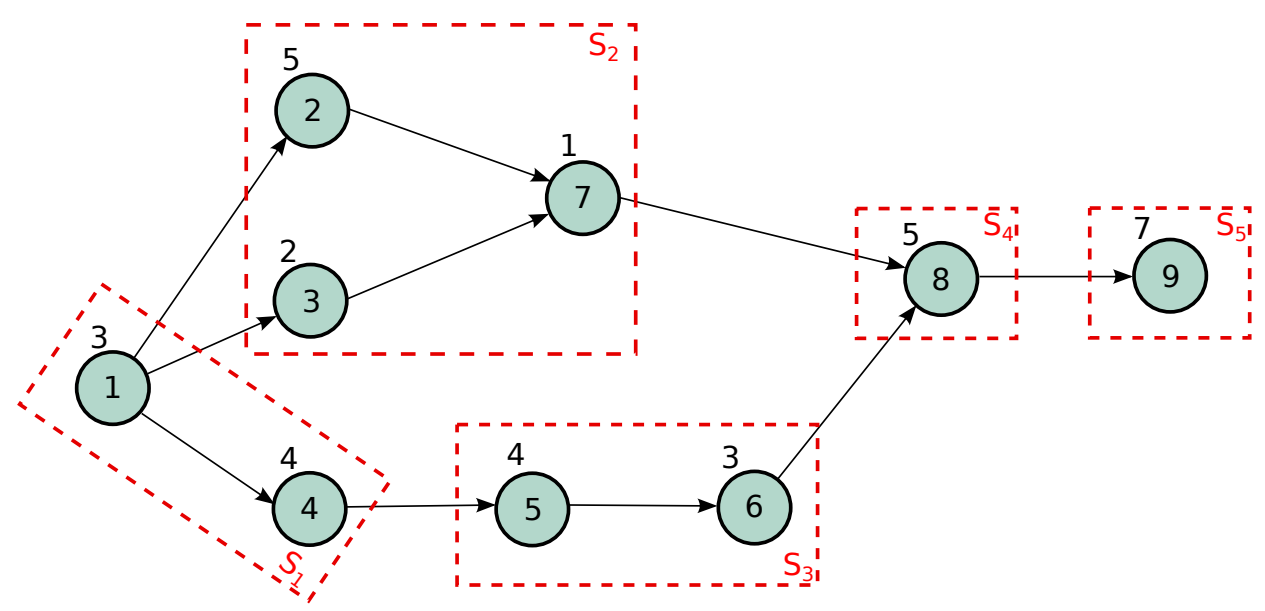

Figura 1 - Exemplo de balanceamento com tempo de ciclo de oito unidades. O conjunto de tarefas $N=\{1,2,3,4,5,6,7,8,9\}$ é particionado em $S_{1}=\{1,4\}, S_{2}=\{2,3,7\}, S_{3}=\{5,6\}, S_{4}=\{8\}$ e $S_{5}=\{9\}$, que correspondem a um balanceamento. Os valores ao lado dos nós indicam os tempos de execução das tarefas correspondentes.

\subsubsection{SALBP}

Problemas para se encontrar balanceamento de linhas de produção têm sido alvos de estudos durante as últimas cinco décadas. O mais simples deles é conhecido como SALBP (Simple Assembly Line Balancing Problem). Nesse problema, busca-se por um balanceamento de uma linha que contém um conjunto finito de tarefas que possuem uma relação de ordem expressa através de um grafo de precedências. Segundo SCHOLL (1999), as características do SALBP são:

$\square$ produção em massa de um único tipo de produto, através da execução de um determinado número de operações para um dado processo produtivo;

$\square$ linhas com tempo de ciclo fixo (ritmadas);

$\square$ tempos de execução das tarefas determinísticos e inteiros;

$\square$ nenhuma restrição de designação além das relações de precedência;

$\square$ leiaute serial da linha com estações de apenas um lado;

$\square$ estações igualmente equipadas;

$\square$ intervalo fixo entre início e o fim da montagem de produtos (tempo de ciclo).

Na literatura, destacam-se as diferentes versões do SALBP: SALBP-F, SALBP-1, SALBP-2 e SALBP-E. O SALBP-F é o problema de factibilidade cuja solução corresponde 
a encontrar um balanceamento dados um número de estações e um tempo de ciclo para a linha de produção. O SALBP-1 herda as características do SALBP-F, contudo, o número de estações de trabalho é uma variável a ser minimizada dado um tempo de ciclo, isto é, deseja-se encontrar a linha de produção com o menor número de estações de trabalho que consiga atender o tempo de ciclo determinado. O SALBP-2 é um problema relacionado ao SALBP-1 no qual a variável a ser minimizada é o tempo de ciclo para uma linha com um determinado número de estações. Por fim, o SALBP-E busca encontrar a combinação de número de estações e tempo de ciclo que otimiza a eficiência da linha, geralmente dada por uma função do tempo ocioso nas máquinas. Uma modelagem para o SALBP-2 é detalhada a seguir, dado que esse é o caso contemplado neste trabalho.

Seja $N$ o conjunto de tarefas. As tarefas $i \in N$ precisam respeitar a ordem dada pelo grafo de precedências e o tempo de execução de cada tarefa $i \in N$ é $t_{i}$. Também, seja $C$ o tempo de ciclo. Definindo-se a variável binária $x_{i k}$, igual a 1 se, e somente se, a tarefa $i$ é alocada na estação $k$, tem-se o modelo do SALBP-2 representado pelas relações (1)-(5).

sujeito a:

$$
\begin{aligned}
\sum_{k \in S} x_{i k}=1, & \forall i \in N, \\
\sum_{i \in N} t_{i} \cdot x_{i k} \leq C, & \forall k \in S, \\
\sum_{k \in S} k \cdot x_{i k} \leq \sum_{k \in S} k \cdot x_{j k}, & \forall i, j \in N, i \lessdot j, \\
x_{i k} \in\{0,1\}, & \forall i \in N, \forall k \in S .
\end{aligned}
$$

O objetivo do modelo (1)-(5) é fornecer um balanceamento que minimiza o tempo de ciclo. As restrições (2) garantem que toda tarefa é executada, enquanto que as restrições (3) definem o tempo de ciclo da linha. As restrições (4) traduzem a ordenação imposta pelo grafo de precedências. O modelo (1)-(5) assume que todas as hipóteses do SALBP são respeitadas. No entanto, muitas das hipóteses raramente são atendidas na prática, em especial, o tempo de execução das tarefas pode depender da estação na qual a tarefa é realizada devido, por exemplo, a trabalhadores com diferentes habilidades alocados às estações. Esse é o caso do ALWABP.

\subsubsection{ALWABP}

Considerando que o conjunto de trabalhadores é heterogêneo (os trabalhadores têm habilidades diferentes), além de se alocar tarefas às estações, é necessário alocar trabalhadores às estações. Esse problema foi proposto por MIRALLES et al. (2007), motivado por características encontradas em linhas de produção em Centros para Trabalhadores 
Deficientes, e é conhecido como ALWABP (Assembly Line Worker Assignment Balancing Problem). De acordo com CHAVES; LORENA; MIRALLES (2009), as principais características do ALWABP são:

os tempos de processamento das tarefas e as relações de precedência são determinísticos;

$\square$ existe um determinado número de trabalhadores e o tempo de execução de cada tarefa varia de acordo com o trabalhador, pois cada trabalhador possui habilidades distintas;

as habilidades entre os trabalhadores diferem bastante. Os trabalhadores podem ser eficientes para algumas tarefas, ineficientes para outras ou mesmo incapazes de realizar algumas tarefas;

cada estação de trabalho deve ter exatamente um trabalhador atribuído a ela;

$\square$ cada tarefa é atribuída somente a uma estação de trabalho e deve-se garantir que o trabalhador alocado à mesma seja capaz de realizá-la e que as relações de precedência sejam respeitadas.

Assim como o SALBP, o ALWABP também se apresenta em diversas versões: ALWABPF, ALWABP-1, ALWABP-2 e ALWABP-E. Analogamente, o ALWABP-1 tem como objetivo reduzir o número de estações e um modelo para o ALWABP-2 busca por soluções minimizadoras do tempo de ciclo.

Visando construir um modelo para o ALWABP, considere o conjunto de tarefas $N$. O tempo de execução de cada tarefa $i \in N$ é determinístico mas depende do trabalhador que a executa. Representa-se por $p_{w i}$ o tempo de processamento da tarefa $i$ quando executada pelo trabalhador $w$. Assim como antes, as tarefas $i \in N$ possuem uma certa ordem de execução dada por um grafo de precedências, a notação $i \lessdot j$ indica que a tarefa $i$ deve terminar antes da tarefa $j$ iniciar e $S$ denota o conjunto de estações de trabalho. Também, seja $W$ o conjunto de trabalhadores. Então, podem-se definir as variáveis binárias $y_{s w}$ (igual a 1 se, e somente se, o trabalhador $w \in W$ é alocado à estação $s \in S$ ) e $x_{\text {swi }}$ (igual a 1 se, e somente se, a tarefa $i \in N$ é executada pelo trabalhador $w \in W$ na estação $s \in S$ ). Além disso, a variável $C$ representa o tempo de ciclo da linha. Dessa forma, pode-se modelar o ALWABP-2 com as relações (6)-(14) apresentadas. 
sujeito a:

$$
\begin{aligned}
\sum_{s \in S} \sum_{w \in W} x_{s w i}=1, & \forall i \in N, \\
\sum_{s \in S} y_{s w}=1, & \forall w \in W, \\
\sum_{w \in W} y_{s w}=1, & \forall s \in S, \\
\sum_{s \in S} \sum_{w \in W} s \cdot x_{s w i} \leq \sum_{s \in S} \sum_{w \in W} s \cdot x_{s w j}, & \forall i, j \in N, i \lessdot j, \\
\sum_{i \in N} \sum_{w \in W} p_{w i} \cdot x_{s w i} \leq C, & \forall s \in S, \\
\sum_{i \in N} x_{s w i} \leq|N| y_{s w}, & \forall s \in S, \forall w \in W, \\
y_{s w} \in\{0,1\}, & \forall s \in S, \forall w \in W, \\
x_{s w i} \in\{0,1\}, & \forall s \in S, \forall w \in W, \forall i \in N .
\end{aligned}
$$

O objetivo do modelo (6)-(14) é obter um balanceamento que minimize o tempo de ciclo da linha de produção. As restrições (7) garantem a execução de todas as tarefas, enquanto que cada trabalhador estar alocado a exatamente uma estação e toda estação ter um trabalhador é garantido pelos conjuntos de restrições (8) e (9), respectivamente. O grafo de precedências das tarefas é traduzido pelas restrições (10) e o respeito ao tempo de ciclo é dado por (11). Por fim, as restrições (12) asseguram que a tarefa e o trabalhador que a executa são alocados à mesma estação.

É possível encontrar variações na literatura para o SALBP e para o ALWABP. Em geral, tais variações surgem ao se flexibilizar uma das características (restrições) que definem os problemas. Por exemplo, podem-se definir problemas considerando a produção de produtos diferentes ou linhas com leiautes alternativos ao serial e suas adaptações para o ALWABP. Uma classificação dos problemas de balanceamento de linhas de produção e métodos para sua solução podem ser encontrados em (BATTAÏA; DOLGUI, 2013) e uma revisão sobre a literatura relacionada a linhas de produção com trabalhadores heterogêneos pode ser encontrada em (MOREIRA; MIRALLES; COSTA, 2015). Em relação ao trabalho deste documento, o objetivo é modificar os modelos apresentados para obter balanceamentos com características específicas, como exposto no Capítulo 4.

\subsection{Simulação}

Simulação é uma imitação de um sistema (ROBINSON, 2004). Sistemas CAD (Computer Aided Design - Design auxiliado por computador) produzindo imitações de uma 
construção civil, um falsificador imitando o objeto copiado, jogos de computador testando a habilidade do jogador em pilotar um automóvel ou construir uma cidade podem ser exemplos de simulações.

Tais simulações possuem uma característica que permite separá-las. Algumas delas representam o sistema imitado em um determinado instante no tempo, enquanto outras imitam o comportamento de um sistema ao longo do tempo. Aquelas são ditas simulações estáticas e estas são denominadas simulações dinâmicas. Também, pode ser feita uma classificação segundo o tipo de sistema imitado (CHECKLAND, 1981): sistemas naturais, com design físico, com design abstrato e de atividade humana. Sistemas naturais são os originados em fenômenos naturais (o clima, modelos atômicos e o sistema solar); fábricas, casas e carros são exemplos de sistemas de design físico que são construídos pelo homem. Enquanto que matemática e literatura são sistemas com design abstrato e sistemas de atividade humana podem ser exemplificados por sistemas políticos e famílias.

É importante destacar que um modelo de simulação não tem objetivo de fornecer uma resposta ótima (como um modelo de programação linear, por exemplo) nem quaseótima (como métodos heurísticos). O objetivo de um modelo de simulação é prever o comportamento de um sistema. Isto é, a entrada de um modelo de simulação é um conjunto de parâmetros e sua saída pode ser entendida como um comportamento possível do sistema para aquele conjunto específico de entrada.

Determinar o comportamento de um sistema de maneira exata (analítica) é, muita vezes, complicado, especialmente se houver variabilidades. Essas variabilidades podem ser razoavelmente previsíveis, como o número de enfermeiras disponíveis ao longo do dia em um hospital ou bastante imprevisíveis; por exemplo, quando e qual será o número máximo de emergências simultâneas que o hospital terá de atender em um determinado dia. Além disso, um sistema é comumente composto por diversos subsistemas e suas interrelações podem conter outras variabilidades; por exemplo, grupos de enfermeiras podem ter atendimentos em diversas áreas do hospital de acordo com a demanda momentânea de cada área. Sistemas com aplicações práticas costumam apresentar diversos graus de variabilidade, interdependência entre subsistemas e complexidade. É nesse contexto que modelos de simulação são particularmente úteis. Esses modelos são capazes de representar variabilidade, interdependência e complexidade de sistemas de forma a prever seu comportamento em diferentes cenários de maneira, em geral, muito mais flexível e precisa do que a obtida com modelos analíticos.

Uma alternativa à simulação seria realizar experimentos com o sistema real. No entanto, interromper a operação de um sistema pode ser custoso. Além de mudanças que podem ser necessárias para os experimentos, é possível que o sistema tenha de ser desligado por algum tempo. Mesmo que fosse possível experimentar com o sistema sem impactos financeiros esse procedimento poderia consumir bastante tempo, enquanto que, em uma simulação computacional, resultados poderiam ser obtidos em minutos ou horas. Ainda, 
simulações permitem um maior controle das condições do experimento, aumentando a confiabilidade dos resultados. Por fim, caso o sistema real ainda não exista, simulação torna-se a única opção disponível.

Por outro lado, simulação não é, necessariamente, um procedimento barato. A modelagem de um sistema pode ser complicada e custosa, além de usualmente requerer grande quantidade de dados para se obter a confiabilidade desejada. Também, a construção e utilização de um modelo requer, entre outros, conhecimentos de programação, modelagem conceitual, estatística, gerenciamento de projeto e habilidades interpessoais, o que pode não estar prontamente disponível.

Como se deseja construir um simulador para avaliação do comportamento de uma linha de produção ao longo do tempo, apresentam-se, a seguir, estratégias para se modelar o avanço do tempo durante uma simulação.

\subsubsection{Modelando o avanço do tempo}

Esta subseção discorre sobre duas possíveis abordagens para se modelar a passagem do tempo em uma simulação dinâmica: discretização do tempo e eventos discretos. A primeira é mais adequada para modelar sistemas de tempo contínuo, por exemplo, a posição de um carro ao longo de uma rodovia ou a temperatura da resistência de um chuveiro enquanto ele está ligado. Já a modelagem do tempo por eventos discretos é mais compatível com sistemas que têm variáveis de estado discretas e cujos eventos identificam uma transição de estado, por exemplo, uma pessoa é detectada por um sensor, que atua trocando o estado de uma lâmpada, ligando-a.

A título de exemplo para uma abordagem de discretização temporal, suponha que se quer simular a velocidade de um automóvel de acordo com as ações do motorista e características do terreno. As entradas do sistema podem ser a posição dos pedais do veículo, a marcha em que o automóvel está e a inclinação do terreno. O simulador, munido dessas variáveis, calcula qual a velocidade do automóvel em um determinado instante de tempo. No instante de tempo seguinte, esse procedimento se repete. No entanto, também é necessário se escolher um passo de tempo para a simulação, isto é, de quanto em quanto tempo o simulador repetirá o procedimento de ler as entradas e calcular a saída para a simulação. A Figura 2 ilustra alguns desses aspectos. A curva indica a saída do sistema e o passo de tempo, $\Delta t$, permite identificar os instantes em que essa saída foi calculada.

Outro exemplo seria um sistema de acionamento de uma escada rolante. Visando economizar energia, a escada fica desligada até que alguém pressione um botão em seu início, então a escada funciona por 30 segundos, levando o passageiro até o topo e desliga novamente. A Figura 3 ilustra a saída desejada para esse exemplo utilizando a técnica de discretização do tempo. A saída do sistema identifica se a escada rolante está ligada $(\mathrm{ON})$ ou desligada $(\mathrm{OFF})$ em cada instante de tempo e os ícones estrelados representam instantes em que o botão foi pressionado. É importante notar que, nessas situações, 


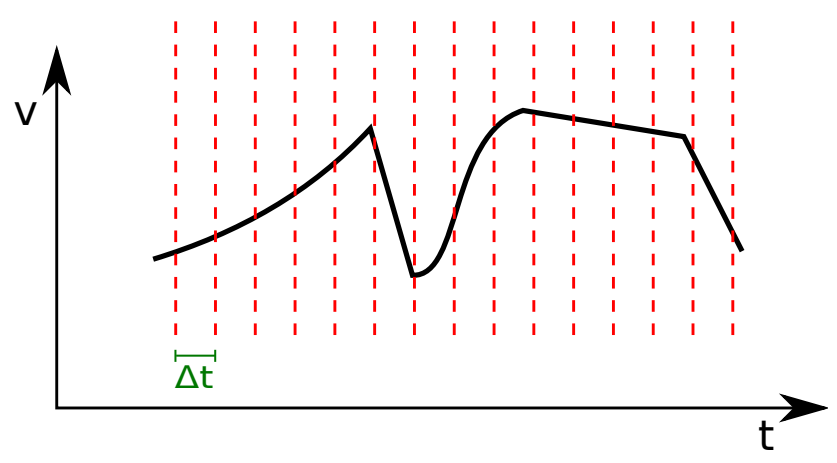

Figura 2 - Exemplo de simulação da velocidade (eixo vertical) de um automóvel ao longo do tempo (eixo horizontal). Quanto menor o passo de tempo, $\Delta t$, maior a precisão da simulação e maior o esforço computacional necessário para realizar toda a simulação.

ocorrem alguns problemas, por exemplo, não há garantia de que a amostragem ocorrerá exatamente ao mesmo tempo em que o botão foi pressionado, também, é discutível se as amostragens que ocorrem enquanto a escada está ligada são necessárias. Isso se deve ao fato desse exemplo ser de uma situação típica de modelo de passagem de tempo baseado em eventos discretos. Utilizando eventos discretos, não se tem um passo de tempo. Nesse caso, o acionamento do botão dispara um evento responsável por ligar a escada e, neste momento, é agendado um novo evento para que a escada desligue após 30 segundos.

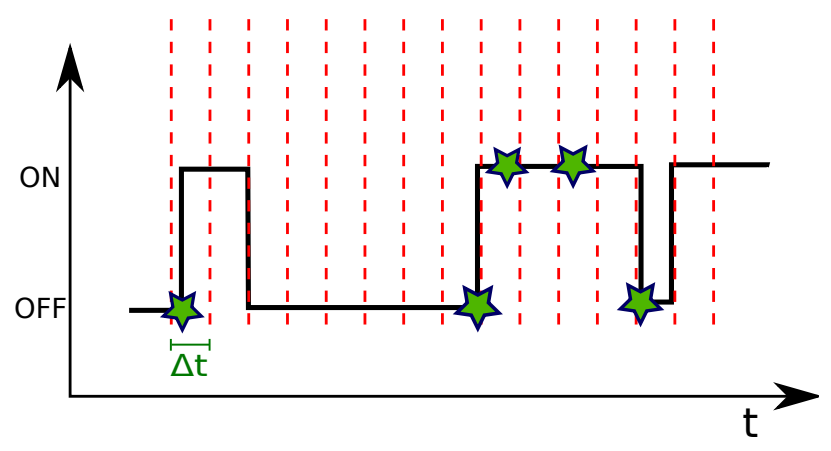

Figura 3 - Exemplo no qual o uso de discretização temporal pode não ser adequado. As estrelas marcam momentos em que o botão foi pressionado. Note que pode ser complicado definir $\Delta t$ de forma a detectar eventos instantâneos. Uma alternativa, então, seria utilizar a técnica de eventos discretos para modelar a passagem do tempo.

Existem alguns mecanismos clássicos para se tratar eventos discretos: baseados em evento, em atividade, em processo e modelos de três fases. A Figura 4 apresenta o modelo de três fases. Para uma discussão sobre os demais modelos ver (PIDD, 1998). Segundo ROBINSON (2004), esses mecanismos são bastante utilizados em pacotes comerciais de simulação.

Em um modelo de três fases, os eventos são divididos em dois tipos: B (booked, agendados) ou C (condicionais). Os eventos do tipo B acontecem em um tempo específico e são, previamente, agendados; por exemplo, daqui a dois minutos, o atendente terminará sua tarefa. Os eventos do tipo C são dependentes de alguma condição do modelo, por exemplo, um atendente só pode começar a servir um cliente se existe um cliente esperando 


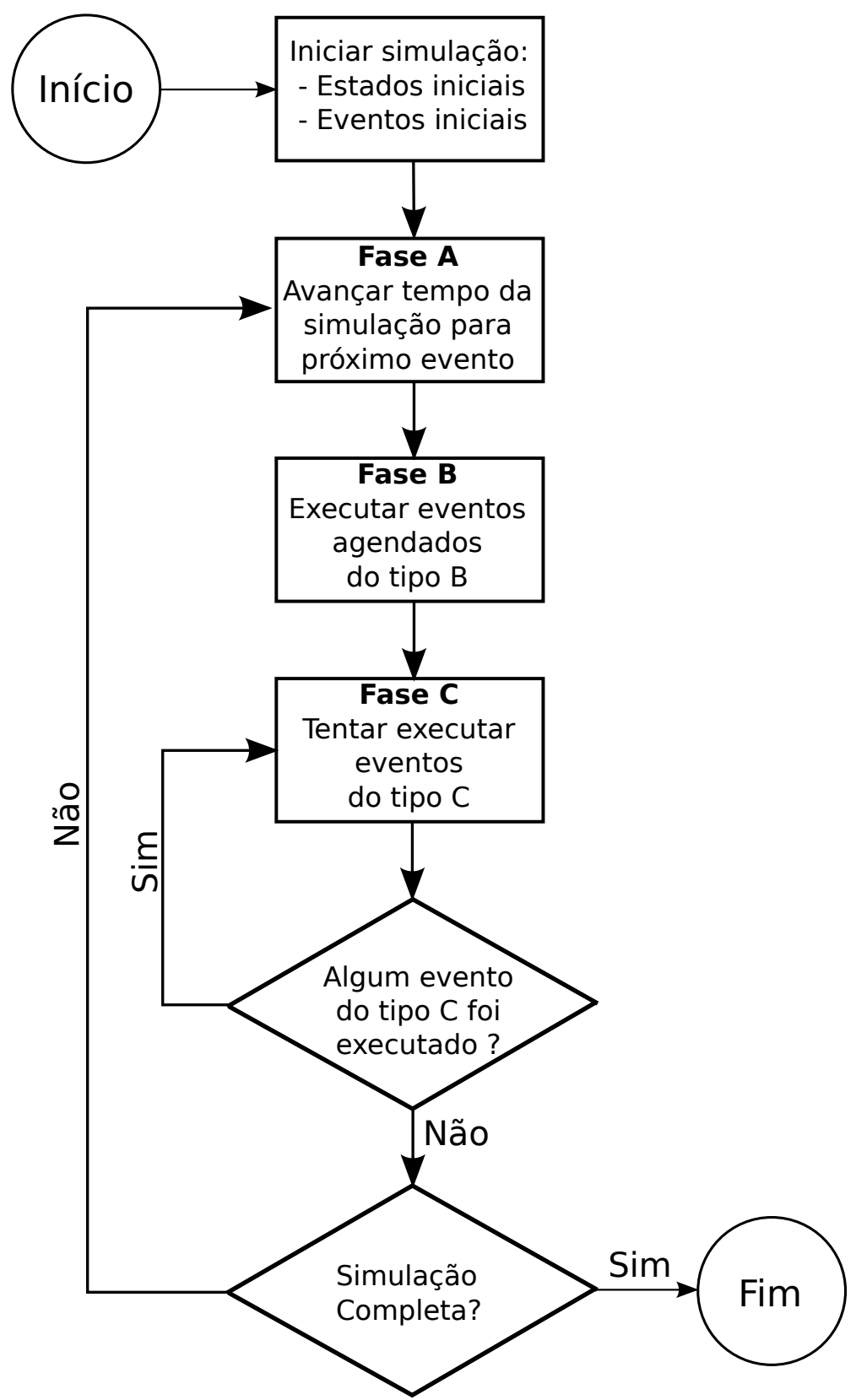

Figura 4 - Abordagem de três fases para simulação de eventos discretos: as fases A, B e C se repetem ciclicamente até que o critério de parada da simulação seja atingido. Figura adaptada de (ROBINSON, 2004).

para ser atendido. Em geral, eventos do tipo C estão associados ao começo de alguma atividade.

Uma simulação utilizando um modelo de três fases é iniciada determinando-se o estado inicial do modelo e os eventos iniciais do tipo B são agendados. Os eventos agendados são colocados em uma fila que mantém todos os eventos a serem executados no futuro. Em seguida, a simulação entra no laço das três fases: na fase A, o instante do próximo evento é determinado e a simulação avança; na fase $\mathrm{B}$, todos os eventos do tipo $\mathrm{B}$ são executados; na fase $\mathrm{C}$, todos os eventos condicionais tentam ser executados, se algum deles for executado, tenta-se executar algum outro evento condicional. Caso não seja possível 
executar nenhum evento do tipo $\mathrm{C}$ na respectiva fase, verifica-se se a simulação terminou e, em caso negativo, retorna-se a fase A.

Apesar da simplicidade dos exemplos utilizados nesta subseção, pode-se notar que a escolha do mecanismo para simular a passagem do tempo pode afetar os resultados desejados e, portanto, deve ser feita com atenção, de forma a garantir resultados úteis para as pessoas interessadas. O modelo de simulação desenvolvido neste trabalho utiliza eventos discretos e está descrito na Seção 4.2.

\subsection{Outros conceitos}

Esta seção apresenta alguns conceitos que foram utilizados para o desenvolvimento deste trabalho. Esses são conceitos importantes para permitir a reprodutibilidade do trabalho. No entanto, acredita-se que eles não sejam essenciais para um entendimento em alto nível das questões aqui exploradas.

\subsubsection{Métodos de Monte Carlo}

Métodos de Monte Carlo são meios de se introduzir incerteza (probabilidades) na análise de um sistema. São uma ampla classe de algoritmos computacionais que se utilizam de repetição e amostragem para obter resultados numéricos sobre um sistema. Em geral, são utilizados em análises nas quais é difícil (ou impossível) obter uma expressão analítica para a situação estudada. Esses métodos são aplicados em diversas áreas, por exemplo: medicina (LEE et al., 2012), finanças (BERNARD; BOYLE, 2011), astrofísica (LUDWIG; HUEGE, 2011) e sistemas elétricos (TEKINER; COLT; FELDER, 2010).

Métodos de Monte Carlo variam quanto à estrutura, mas podem ser definidos da seguinte forma. Primeiramente, são definidas as variáveis de entrada e seus domínios. Então, são geradas entradas aleatórias e calculadas suas respectivas saídas. Por fim, são agregados os resultados de forma a contribuir para a análise do sistema em estudo. Como exemplo, considere que se quer estimar o valor de $\pi$. Para isso, pode-se definir um um quadrado de lado unitário e um quarto de circunferência, também de raio unitário, inscrito nele, como ilustrado na Figura 5. Em seguida, usando como entrada duas variáveis aleatórias correspondentes aos eixos horizontal e vertical, que podem assumir valores reais no intervalo $[0,1]$, geram-se valores para essas duas entradas seguindo uma distribuição uniforme. Assim, a razão entre o número de pontos gerados que estão dentro do quarto de circunferência e dos pontos fora dela é uma aproximação para $\frac{\pi}{4}$. Portanto, o quádruplo dessa razão é uma aproximação para $\pi$. Quanto maior o número de pontos gerados no experimento, melhor será essa aproximação.

Nesse trabalho, foi utilizado um método de Monte Carlo para avaliar o desempenho das alocações geradas pelos modelos de programação inteira mista. Cada alocação gerada está 


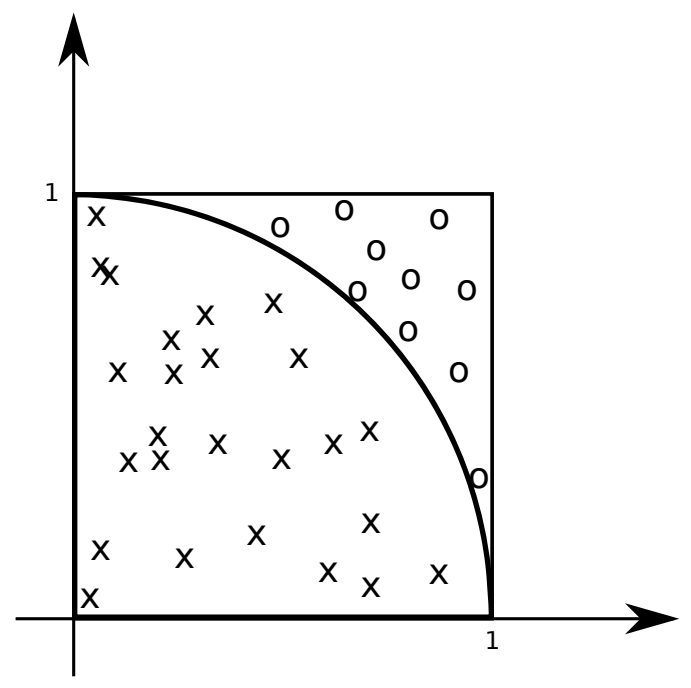

Figura 5 - Exemplo de aplicação do método de Monte Carlo. A área do quarto de circunferência de raio unitário é $\frac{\pi}{4}$. Conforme são gerados pontos dentro do quadrado unitário, a razão entre o número de pontos dentro da circunferência (marcados com "x") e fora dela (mas dentro do quadrado - marcados com "o") é uma aproximação para o valor de $\frac{\pi}{4}$ e, quanto maior o número de pontos gerados, mais precisa é a aproximação.

associada a parâmetros estocásticos do modelo de simulação. Então, um método de Monte Carlo é utilizado, realizando um número pré-determinado de repetições, que são agregadas e possibilitam a utilização de testes de hipótese para comparação de desempenho entre tais alocações.

\subsubsection{Simulação-otimização}

Neste trabalho foram utilizadas técnicas de otimização e simulação em conjunto, organizadas de maneira a permitir a exploração das questões de pesquisa. Essa combinação pode ser feita de diversas maneiras: pode-se utilizar otimização para encontrar bons parâmetros para o modelo de simulação, a simulação pode contribuir para a melhora de modelos analíticos ou a simulação pode gerar resultados baseada nas soluções fornecidas pelos modelos de otimização. FIGUEIRA; ALMADA-LOBO (2014) propõem uma taxonomia para classificação das possibilidades de se combinar otimização e simulação. Também em (FIGUEIRA; ALMADA-LOBO, 2014), há exemplos de diversos trabalhos e como eles se encaixam na taxonomia proposta.

Alguns exemplos de trabalhos que utilizam simulação-otimização são: (BRUNET et al., 2012), (SRIVASTAV; SRINIVASAN; SUDHEER, 2011) e (AQLAN; LAM; RAMAKRISHNAN, 2014). Em (BRUNET et al., 2012) é proposto um modelo de otimização dinâmica inteira mista que é resolvido por um método de decomposição e os subproblemas primais gerados têm solução dependente de um modelo de simulação. SRIVASTAV; SRINIVASAN; SUDHEER (2011) propuseram um arcabouço que permite a automação de um processo para geração sintética de vazões de água multi-sazonal. Nesse trabalho, um modelo de 
simulação é embutido em um modelo multi-objetivo estocástico com a proposta de melhorar o desempenho de simulações de vazões para planejamento do uso de água. AQLAN; LAM; RAMAKRISHNAN (2014) investigaram, com ajuda de um modelo de simulação, a consolidação de uma linha de produção e, devido aos resultados obtidos, construíram um modelo de otimização para propor soluções mais adequadas para o estudo de caso considerado.

É importante destacar que este trabalho não propõe nenhum arcabouço ou esquema de combinação das técnicas de simulação e otimização. Apenas se utiliza dessas ferramentas, utilizando um modelo de simulação estocástica para avaliar soluções obtidas com modelo de programação inteira mista, para explorar o efeito Tigela considerando características específicas. São essas características que estão no cerne da contribuição deste trabalho.

\subsubsection{Testes de hipótese}

Testes de hipótese são ferramentas de inferência estatística que têm como objetivo verificar afirmações feitas sobre um conjunto de dados. Isto é, feita uma afirmação (hipótese) sobre uma população, usualmente sobre um parâmetro dessa, deseja-se saber se os resultados de experimentos provenientes de uma amostra contrariam ou não tal afirmação (MORETTIN; Bussab, 2003). Por exemplo, os pais de uma criança desconfiam que seu filho tem uma habilidade para a escrita acima da média. No entanto, como não são especialistas, pedem para um experiente professor de educação básica avaliar um conjunto de redações escritas pelo menino. Por sua experiência, o professor sabe que a média de erros ortográficos em redações do mesmo tamanho é de uma dezena, com um desvio-padrão de duas unidades, para crianças da mesma idade. No conjunto que lhe foi entregue há, em média, seis erros ortográficos por redação. Com essas informações, o professor formula a hipótese de que a criança tem um desempenho equivalente ao de pessoas da sua idade. Para testar sua hipótese, o professor verifica a probabilidade de uma redação com seis erros acontecer em uma população cuja média é dez e o desvio-padrão dois. Isso pode ser feito utilizando a distribuição Normal padronizada. Assim, o professor calcula que a probabilidade em questão é de $2,3 \%$, ou seja, baseado apenas na ortografia, na experiência do professor e nas redações fornecidas, o desempenho da criança está entre os 2,3\% melhores. Portanto, a hipótese inicial do professor está incorreta, pois a criança tem um desempenho melhor do que 97,7\% das crianças de sua idade. Graficamente, o exemplo é pode ser ilustrado como na Figura 6.

Apesar de ser um exemplo simples e hipotético, ele ilustra a ideia de um teste de hipótese. Essa ideia foi desenvolvida e adaptada para testes sobre a média de uma população com variância conhecida, testes para proporção, testes para variância de uma distribuição Normal, testes sobre a média de uma distribuição Normal com variância desconhecida (teste-t). O desenvolvimento de testes de hipótese para cada uma dessas situações pode ser encontrado em (MORETTIN; BUSSAB, 2003). Neste trabalho, foi utilizado o teste-t para 


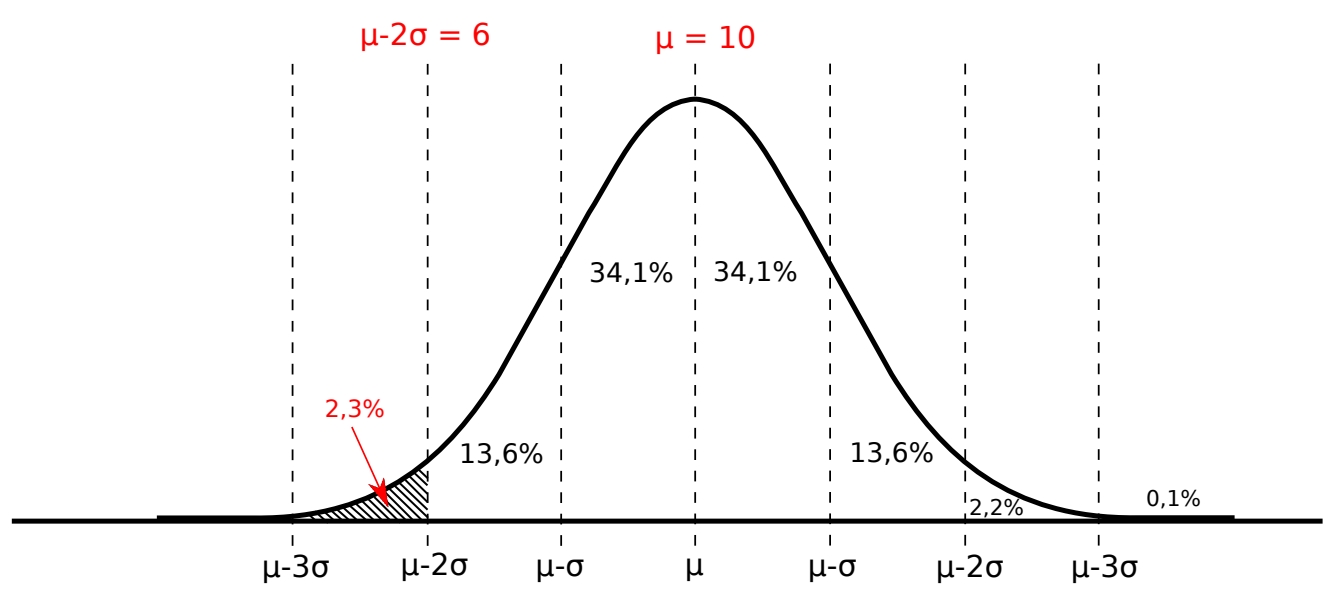

Figura 6 - A curva Normal ilustra o conhecimento do professor sobre os erros ortográficos de alunos de uma determinada faixa etária $(\mu=10$ e $\sigma=2)$. O aluno a ser classificado possui um desempenho médio equivalente a $\mu-2 \sigma=6$, significando que apenas $2,3 \%$ da população considerada possuem um desempenho melhor (menos erros) que o do aluno no quesito ortografia. As porcentagens na figura indicam a área da faixa delimitada pelas linhas tracejadas em relação a área total da curva.

comparar o desempenho de duas amostras resultantes do modelo de simulação. Especificamente, ele foi utilizado para garantir que os resultados das simulações para diferentes profundidades de tigela são, de fato, diferentes.

Alguns exemplos de trabalhos envolvendo linhas de produção que utilizam teste de hipóteses são: (EL-RAYAH, 1979) e (LAU, 1992). Além disso, alguns trabalhos investigando desbalanceamentos de linhas de produção ou o próprio efeito Tigela também utilizaram-se do teste-t para comparação de desempenhos: (SMUNT; PERKINS, 1985), (SMUNT; PERKINS, 1989), (KARWAN; PHILIPOOM, 1989) e (HONG et al., 2013). 


\section{Revisão da literatura}

Esta seção apresenta trabalhos relacionados ao estudo reportado neste documento. Especificamente, a seção trata de trabalhos relacionados ao desbalanceamento de linhas de produção estocásticas e seus efeitos, em especial o fenômeno Tigela. Os trabalhos são apresentados em ordem cronológica desde pouco antes da descoberta do efeito Tigela (1966) até os dias atuais, passando por um período em que o efeito foi contestado (19721989). Também é apresentada uma tabela com características relevantes dos trabalhos diretamente relacionados ao efeito Tigela como proposto por HILLIER; BOLING (1966).

Os primeiros estudos sobre balanceamento de linhas de produção não-ritmadas (estocásticas) datam de 1962, quando foram feitas simulações para avaliar configurações iniciais de buffers (BARTEN, 1962). Via de regra, os modelos analíticos para o estudo desse tipo de linha de produção são baseados em teoria de filas e, devido aos sistemas de equações resultante, são capazes de lidar, de maneira exata, apenas com cenários reduzidos (poucas estações). Ainda assim, necessitam de hipóteses simplificadoras para que se possa alcançar alguma conclusão, por exemplo, assumir que os tempos de tarefas seguem uma distribuição Exponencial, o que não representa a realidade da maioria das linhas de produção. Na literatura, casos mais realistas, com maior número de estações e/ou distribuições mais adequadas, são comumente estudados utilizando simulação.

Foi utilizando a hipótese de que os tempos das estações seguem uma distribuição Exponencial que, após especulações de que se deveriam intercalar estações lentas e rápidas (PATTERSON, 1964), HILLIER; BOLING (1966) mostraram que a alocação ótima para linhas estocásticas consistia em alocar menos carga às estações centrais como exemplificado na Figura 7, o que denominou-se de efeito Tigela (Bowl phenomenon). Esses resultados consideraram linhas com até quatro estações e buffers com capacidade de zero a quatro unidades. Em 1967, resultados e procedimentos numéricos, derivados do trabalho de HUNT (1956), para estimar a vazão de uma linha estocástica balanceada considerando distribuições Exponencial ou Erlang, foram apresentados em HILLIER; BOLING (1967).

Assumindo-se distribuição Exponencial dos tempos de execução das tarefas não é possível saber se a melhoria obtida pelo efeito Tigela se deve ao desbalanceamento da carga 


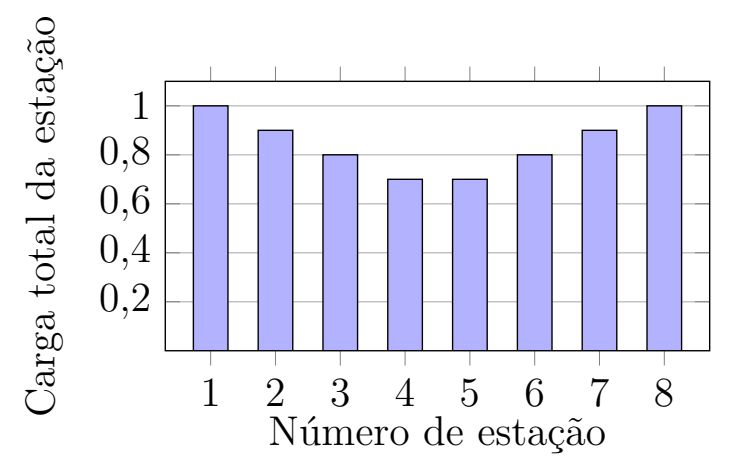

Figura 7 - Exemplo de alocação característica do efeito Tigela: as estações centrais menos carregadas que as estações das extremidades.

média de cada estação ou de sua variabilidade, visto que média e desvio-padrão são iguais para tal distribuição. Explorando essa lacuna, RAO (1975) mostrou que, para um sistema com duas estações, é melhor alocar uma carga ligeiramente maior para a estação com menor variabilidade. Também, RAO (1976) avaliou uma alocação com perfil Tigela para a média contrapondo-a a uma alocação que carrega mais as estações menos variáveis e mostrou que o ótimo foi uma combinação das duas estratégias. Para isso, foram considerados sistemas com três estações e estudadas as combinações possíveis entre estações com tempo seguindo uma distribuição Exponencial e estações com tempos determinísticos.

Estudos seguintes mostraram que trocar a distribuição Exponencial pela Erlang também resulta em alocação ótima do tipo tigela. Foi estudado como essa alocação mudou com o aumento do número de estações e a variabilidade no tempo de processamento (HILLIER; BOLING, 1979) e concluiu-se que um maior número de estações melhorou a taxa de produção média em relação ao caso balanceado; caso a variabilidade fosse alta, aumentar a capacidade dos buffers diminuiu o desbalanceamento médio ótimo. Também, no mesmo período, foram realizadas as primeiras simulações corroborando o efeito Tigela (EL-RAYAH, 1979) como proposto por HILLIER; BOLING (1966).

Em certo momento, surgiram resultados conflitantes relacionados à taxa de produção e ao tempo ocioso de estações em linhas não-ritmadas. Por exemplo, PAYNE; SLACK; R. (1972) defenderam que a alocação decrescente presente em (DAVIS, 1966) seria melhor que a alocação tigela de HILLIER; BOLING (1966), o que foi apoiado por KALA; HITCHINGS (1973), Nesse contexto, KOTTAS; LAU (1981) propuseram uma abordagem para estudo e monitoramento do comportamento transiente das linhas, reportando características que foram subestimadas em estudos prévios e mostrando que os resultados conflitantes da literatura eram originados de interpretação de resultados transientes lidos como resultados de regime permanente.

Outra polêmica aconteceu com a publicação de SMUNT; PERKINS (1985). Segundo os autores, a literatura existente até o momento mostrava que o efeito Tigela ocorria se a variância das tarefas fosse grande (distribuição Exponencial). Um desbalanceamento nos 
níveis de buffer privilegiando estações centrais também era ótimo assumindo grande variabilidade. A taxa de produção diminuía com o aumento do número de estações e com o aumento da variância e melhorava com o aumento da capacidade dos buffers. No entanto, as linhas de produção estudadas, com poucas estações e alta variabilidade, não teriam importância prática de acordo com DUDLEY (1963). Então, SMUNT; PERKINS (1985) apresentaram resultados para casos que seriam mais realistas e, para esses casos, uma alocação do tipo tigela degradou a eficiência da linha. No entanto, KARWAN; PHILIPOOM (1989) e SO (1989), independentemente, argumentaram que o trabalho (SMUNT; PERKINS, 1985) possuía algumas falhas com relação ao planejamento experimental. Os três trabalhos concordaram que era necessário estudar situações mais próximas à realidade.

Em (MUTH; ALKAFF, 1987) foi apresentado um novo método para avaliação do efeito de se desbalancear, independentemente, a média e o desvio-padrão dos tempos de execução. Para tal análise foram utilizadas linhas com três estações e os modelos apresentados tinham relação com alguns estudados previamente como os de HILLIER; BOLING (1966) e RAO (1976). Além disso, LAU (1992) analisou como o fator de utilização de uma linha balanceada foi afetado por diferentes alocações de variabilidade e os resultados foram comparados com os obtidos em outros estudos.

HILLIER; SO (1993) apresentaram resultados numéricos para casos maiores (seis estações) do que os previamente considerados e foram propostas diretrizes para estimar a alocação ótima de casos ainda maiores. Também, os resultados apresentados indicaram que a melhora, em relação ao caso perfeitamente balanceado, aumentou com o número de estações. HILLIER; SO (1996) examinarama robustez do efeito Tigela, isto é, as consequências de se estimar incorretamente a alocação ótima; os resultados mostraram que erros de até $50 \%$ no desbalanceamento ótimo ainda permitem explorar o potencial do efeito Tigela. Além disso, erros de até $10 \%$ na carga individual das estações ainda produziram uma alocação vantajosa em relação à solução perfeitamente balanceada. Por fim, os autores concluíram que buscar uma alocação com perfil de tigela proporcionaria melhores resultados do que buscar uma alocação perfeitamente balanceada, mesmo em casos de erros relativamente grandes nas estimativas.

Em (TEMPELMEIER, 2003) foi, novamente, discutida a aplicabilidade dos modelos e algoritmos da literatura de balanceamento de linhas de produção com interrupções e tempos estocásticos. TEMPELMEIER (2003) afirmou que, na prática, os projetistas de linhas de produção não utilizam ferramentas analíticas, apenas simulação, e que a maioria dos problemas são atacados com uma abordagem de tentativa e erro. Também, assim como em (DUDLEY, 1963), relatou que o coeficiente de variação das tarefas em situações práticas é consideravelmente menor do que uma unidade. Além disso, não seria raro encontrar situações em que as linhas de produção são formadas por 50 ou 100 estações, ou seja, os casos estudados na literatura não estariam compatíveis com situações encontradas na prática. 
Em (HILLIER; HILLIER, 2006), foi mostrado que se a capacidade total de buffers for pequena, ela deveria ser tipicamente balanceada enquanto que a alocação de carga deveria seguir o padrão tigela, se o objetivo for otimizar conjuntamente a carga e a capacidade total de buffers. Considerando como objetivos a minimização do tempo total, do tempo ocioso ou do tempo médio de um produto no sistema (DAS et al., 2010) e (DAS et al., 2010a) investigaram por meio de simulação as alocações do tipo tigela, tigela invertida (com estações mais carregadas no centro da linha) e crescente. Os resultados mostraram que uma alocação do tipo tigela foi melhor para minimizar o tempo total de produção com tarefas seguindo uma distribuição Normal. Também, em (DAS et al., 2012), foram comparadas as alocações crescente e decrescente e os resultados mostraram que, via de regra, a alocação crescente foi superior para os critérios de minimização de tempo total e tempo ocioso, enquanto que a alocação decrescente foi marginalmente superior para se minimizar o tempo médio de uma peça no sistema.

SHAABAN; MCNAMARA; ATIL (2011) estudaram o comportamento de linhas de produção considerando desbalanceamento na média, na variabilidade dos tempos ou na capacidade dos buffers. Para a média dos tempos, uma alocação do tipo tigela apresentou menor tempo ocioso e menores níveis de buffer em relação ao caso balanceado; para a variabiliade, o menor tempo ocioso foi obtido com uma alocação do tipo tigela e o menor nível de buffer com uma alocação descrescente. Por outro lado, para desbalanceamento nos níveis de buffer, o menor tempo ocioso foi obtido por uma alocação balanceada e os menores níveis de buffer ocorreram nos casos em que a capacidade dos buffers no fim da linha eram maiores. HILLIER (2013) apresentou resultados para a otimização conjunta de tamanho de buffers entre as estações e alocação de trabalho fornecendo soluções exatas para casos com três e quatro estações com distribuição Exponencial e Erlang e sugerindo heurísticas para casos maiores.

Os trabalhos relacionados à investigação do efeito Tigela consideram, principalmente em trabalhos cujo o foco é analítico (e não simulação), as distribuições de probabilidade Exponencial ou Erlang para os tempos das estações, como pode ser visto na Tabela 1. No entanto, existem ferramentas para análises com tempos seguindo distribuições gerais, embora muitas delas sejam abordagens aproximadas ou adequadas apenas para casos reduzidos (PAPADOPOUlOS; HEAVEY, 1996). Também, podem ser considerados casos mais complexos, com distribuições probabilísticas gerais, falhas nas estações e produção imperfeita (TEMPELMEIER; BÜRGER, 2001).

É importante destacar que nenhum dos trabalhos mencionados neste capítulo contempla o fato das tarefas, em uma linha de produção real, serem indivisíveis e é esta a principal lacuna que este trabalho explora. Essa lacuna havia sido apontada por outros trabalhos, como (TEMPELMEIER, 2003). No entanto, não é de conhecimento do autor um trabalho analisando tal aspecto. A metodologia para exploração dessa característica, visando responder as questões de pesquisa, é detalhada no Capítulo 4. 
Tabela 1 - Algumas características de trabalhos na literatura acerca do efeito Tigela. A coluna Análise se refere à técnica utilizada para estudar o efeito: analítica ou simulação. A coluna Estações se refere ao número máximo de estações utilizado na análise. A coluna Distribuição identifica a(s) distribuição(ões) de probabilidade(s) considerada(s) e, por fim, a coluna Efeito Tigela diferencia estudos com conclusões a favor ou contra o efeito Tigela. (O trabalho (KALA; HITCHINGS, 1973), não especifica a distribuição com viés positivo que foi utilizada, por isso a expressão "viés positivo" se encontra na célula correspondente). Nesta tabela foram incluídos apenas trabalhos que fornecem argumentos, mesmo que implícitos, a favor ou contra o efeito Tigela como apresentado por HILLIER; BOLING (1966).

\begin{tabular}{|c|c|c|c|c|}
\hline Trabalho & Análise & Estações & Distribuição & $\begin{array}{l}\text { Efeito } \\
\text { Tigela }\end{array}$ \\
\hline (HILLIER; BOLING, 1966) & Analítica & 4 & Exponencial & A favor \\
\hline (HILLIER; BOLING, 1967) & Analítica & 6 & $\begin{array}{c}\text { Erlang e } \\
\text { Exponencial }\end{array}$ & A favor \\
\hline$(\mathrm{RAO}, 1976)$ & Analítica & 3 & Exponencial & A favor \\
\hline (HILLIER; BOLING, 1979) & Analítica & 6 & $\begin{array}{c}\text { Erlang e } \\
\text { Exponencial }\end{array}$ & A favor \\
\hline (PAYNE; SLACK; R., 1972) & Simulação & 20 & Normal & Contra \\
\hline (KALA; HITCHINGS, 1973) & Simulação & 4 & $\begin{array}{c}\text { Normal e } \\
\text { viés positivo }\end{array}$ & Contra \\
\hline (EL-RAYAH, 1979) & Simulação & 12 & $\begin{array}{c}\text { Exponencial, } \\
\text { Normal e } \\
\text { Log-normal }\end{array}$ & A favor \\
\hline (SMUNT; PERKINS, 1985) & Simulação & 8 & Normal & Contra \\
\hline (MUTH; ALKAFF, 1987) & Analítica & 3 & Exponencial & A favor \\
\hline$(\mathrm{SO}, 1989)$ & Simulação & 8 & Normal & A favor \\
\hline (LAU, 1992) & Simulação & 19 & Normal & A favor \\
\hline (HILLIER; SO, 1993) & Analítica & 9 & $\begin{array}{c}\text { Erlang e } \\
\text { Exponencial }\end{array}$ & A favor \\
\hline (HILLIER; SO, 1996) & Analítica & 7 & $\begin{array}{c}\text { Erlang e } \\
\text { Exponencial }\end{array}$ & A favor \\
\hline (HILLIER; HILLIER, 2006) & Analítica & 5 & $\begin{array}{c}\text { Erlang e } \\
\text { Exponencial }\end{array}$ & A favor \\
\hline (DAS et al., 2010) & Simulação & 6 & $\begin{array}{c}\text { Normal e } \\
\text { Exponencial }\end{array}$ & A favor \\
\hline (DAS et al., 2010a) & Simulação & 6 & Normal & A favor \\
\hline (SHAABAN; MCNAMARA; ATIL, 2011) & Simulação & 8 & Weibull & A favor \\
\hline (HILLIER, 2013) & Simulação & 4 & $\begin{array}{c}\text { Erlang e } \\
\text { Exponencial }\end{array}$ & A favor \\
\hline
\end{tabular}




\section{Metodologia de desenvolvimento}

Este capítulo tem o objetivo de apresentar como os conceitos expostos no Capítulo 2 podem ser utilizados para explorar a lacuna presente na literatura em relação ao efeito Tigela, tendo em vista as questões de pesquisa definidas. Mais especificamente, a Seção 4.1 propõe modificações nos modelos do SALBP e do ALWABP capazes de induzir a geração de soluções com o formato de tigela. A Figura 8 resume a estratégia que será detalhada neste capítulo: na Seção 4.2 é descrito o modelo de simulação desenvolvido capaz de explorar as soluções fornecidas pelos modelos de programação inteira mista que contemplam a integralidade das tarefas, abordados na Seção 4.1.

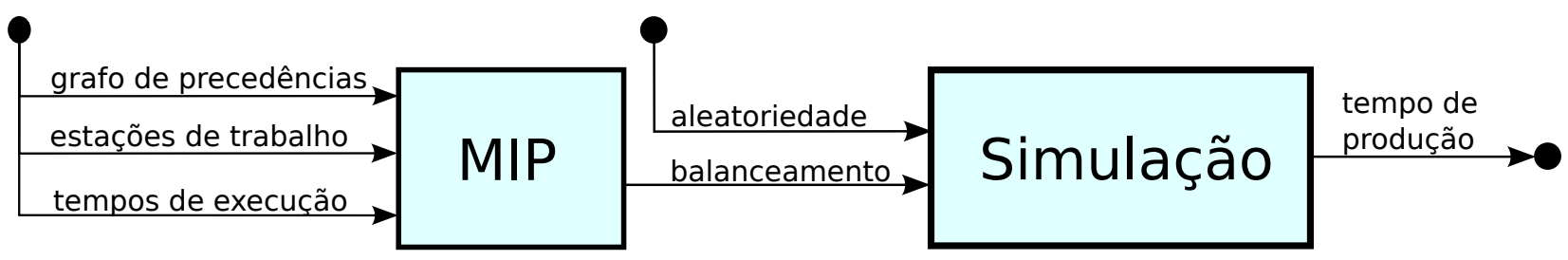

Figura 8 - Esquema geral da solução utilizada para determinar a produtividade de linhas estocásticas a partir de soluções determinísticas de um modelo de programação inteira mista. O MIP recebe como entrada uma instância, isto é, o grafo de precedências entre as tarefas, o número de estações de trabalho e o tempo de execução das tarefas (no caso do ALWABP, segundo o trabalhador que as executam). Esse modelo fornece um balanceamento que, em conjunto com a hipótese de que os tempos de execução das tarefas seguem uma distribuição Normal, é utilizado como entrada para um modelo de simulação. Por fim, após a simulação, tem-se o tempo necessário para a produção de uma quantidade pré-determinada de itens.

\subsection{Geração de soluções tigela}

Primeiramente, se faz necessário definir quais são os parâmetros que se deseja desbalancear para avaliação. Foi escolhido que os tempos de execução das tarefas são regidos por uma distribuição Normal, pois, segundo TEMPELMEIER (2003), esta distribuição é mais adequada que as distribuições Exponencial ou Erlang para modelar a aleatoriedade envolvida em linhas de produção não-ritmadas e, talvez por isso, também é bastante comum nos 
trabalhos citados no Capítulo 3. Sendo assim, pretende-se analisar independentemente os desbalanceamentos com relação à média e ao desvio-padrão. A média foi assumida numericamente igual aos tempos determinísticos das tarefas das instâncias originais de (OTTO; OTTO; SCHOLL, 2013) descritas na Seção 5.1, enquanto que o desvio-padrão é arbitrado de forma a se obter o padrão desejado.

Em relação à média, são propostas alterações nos modelos do SALBP e do ALWABP de forma a favorecer soluções que apresentem o perfil de tigela. Considerando a superioridade de balanceamentos do tipo tigela, relatada na literatura, os conjuntos de restrições (3) e (11) seriam adequadas ao caso determinístico, no qual se busca por uma alocação perfeitamente balanceada. Para favorecer soluções com perfil de tigela, no SALBP, podem-se substituir as restrições (3) por:

$$
\sum_{i \in N} t_{i} \cdot x_{i s} \leq \alpha_{s} C, \quad \forall s \in S
$$

e, para o ALWABP, as restrições relativas ao tempo de ciclo podem ser substituídas por:

$$
\sum_{i \in N} \sum_{w \in W} p_{w i} \cdot x_{s w i} \leq \alpha_{s} C, \quad \forall s \in S
$$

em ambos os casos $\alpha_{s}, s \in S$, é um parâmetro que tem o objetivo de induzir alocações com perfil de tigela, isto é, alocações simétricas e com as estações centrais menos carregadas. A simetria pode ser garantida fazendo:

$$
\alpha_{|S|-s+1}=\alpha_{s}, \quad s=1 \ldots\lfloor|S| / 2\rfloor .
$$

Assim, para o SALBP, por exemplo, se o número de estações $|S|=5$, tem-se $\alpha_{5}=\alpha_{1}$ e $\alpha_{4}=\alpha_{2}$. Ou seja, existe um limitante de tempo de ciclo, $\alpha_{s} C$, para a primeira e última estações, outro para a segunda e a penúltima estações, e um terceiro para a estação central. Para se induzir uma alocação do tipo tigela, ainda é necessário garantir que as estações tenham um limitante menor conforme sua proximidade com a estação central. Isso pode ser obtido da seguinte forma:

$$
\alpha_{s}=\beta \alpha_{s-1}, \quad s=2 \ldots\lceil|S| / 2\rceil .
$$

Dessa forma, desde que $0<\beta<1$, os limitantes de tempo de ciclo diminuem da primeira estação até a central com um fator $\beta$ e, pelas equações de simetria (17), as estações da segunda metade da linha também têm seus limitantes diminuindo da última estação até o centro. Portanto, escolhendo-se os parâmetros $\alpha_{s}>0$ e $\beta \in(0,1]$ pode-se induzir perfis de carga no formato de tigela com diferentes profundidades. Por exemplo, com $\alpha_{1}=1, \beta=0,7$ e $|S|=5$, as relações (15) se tornam: 


$$
\begin{aligned}
& \sum_{i \in N} t_{i} \cdot x_{i 1} \leq 1 C, \\
& \sum_{i \in N} t_{i} \cdot x_{i 2} \leq 0,7 C, \\
& \sum_{i \in N} t_{i} \cdot x_{i 3} \leq 0,49 C, \\
& \sum_{i \in N} t_{i} \cdot x_{i 4} \leq 0,7 C, \\
& \sum_{i \in N} t_{i} \cdot x_{i 5} \leq 1 C .
\end{aligned}
$$

Note que se $\beta=1$ tem-se os modelos originais correspondentes. Graficamente, outros exemplos de escolhas dos parâmetros $\alpha_{1}$ e $\beta \in(0,1]$ podem ser vistos na Figura 9 .
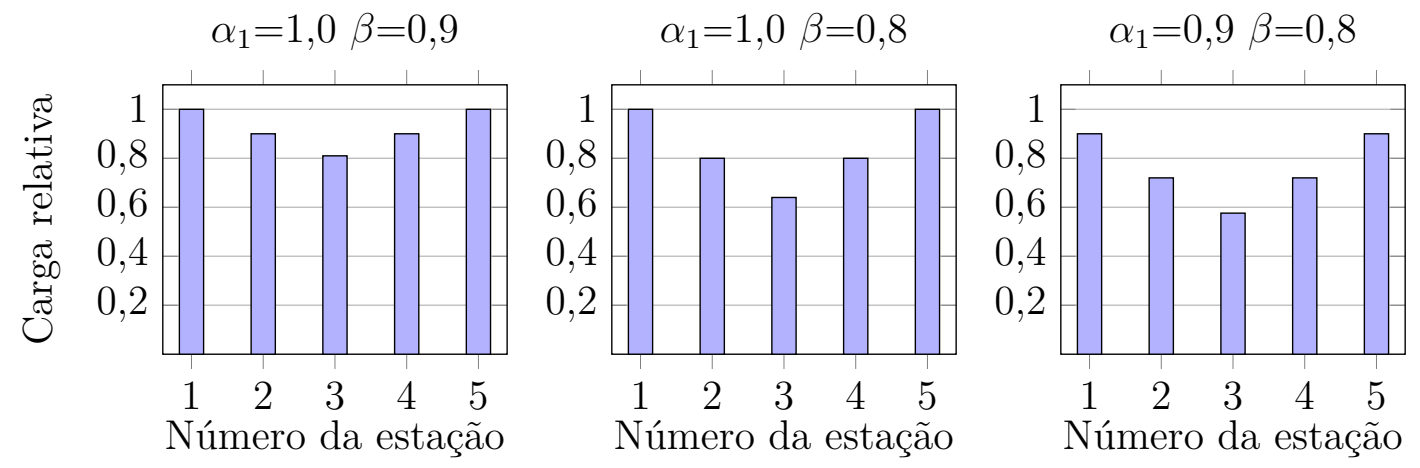

Figura 9 - Balanceamentos induzidos para diferentes valores de $\alpha_{1}>0$ e $\beta \in(0,1]$.

Com esses novos modelos, podem-se obter balanceamentos mais parecidos com perfis Tigela enquanto que os modelos originais buscavam soluções perfeitamente balanceadas. Essas soluções são utilizadas para estudar desbalanceamentos relativos à média. Por outro lado, uma linha de produção estocástica também pode se beneficiar se tarefas com menor variabilidade forem alocadas às estações centrais. Com objetivo de avaliar esse cenário, considere o coeficiente de variação, $c_{s}, s \in S$, que indica o nível de variabilidade de cada tarefa dentro da estação $s$; esse coeficiente é obtido pela razão entre desvio-padrão e média do tempo de execução de qualquer tarefa dentro da estação $s$.

Para tais experimentos, os perfis tigela para $c_{s}, s \in S$, são escolhidos de acordo com as seguintes relações, mantendo-se $\beta=1$ nas equações (18):

$$
\begin{gathered}
c_{1}=0,1 \quad \text { ou } \quad c_{1}=0,2, \\
c_{|S|-s+1}=c_{s}, \quad s=1 \ldots\lfloor|S| / 2\rfloor, \\
c_{s}=\theta c_{s-1}, \quad s=2 \ldots\lceil|S| / 2\rceil,
\end{gathered}
$$

sendo $0<\theta \leq 1$ um parâmetro relacionado com a profundidade da tigela de desvio-padrão (ou coeficiente de variação), análogo ao $\beta$ para os casos da média. É possível notar que 
as relações utilizadas para análise de desbalanceamentos relativos ao desvio-padrão são semelhantes às usadas para a média. Isto é, os padrões analisados podem ter o mesmo formato.

Dessa forma, com as modificações (15) e (16), os novos modelos de programação inteira mista para o SALBP e o ALWABP são capazes de gerar soluções favorecendo padrões de alocação do tipo tigela (Figura 7). A contribuição mais expressiva ligada a esses modelos está no fato da indivisibilidade das tarefas ser considerada para posterior análise do efeito Tigela. Além disso, definiu-se uma estratégia para geração de desbalanceamento em relação a variabilidade das tarefas para se avaliar o efeito de centralizar tarefas com menor variabilidade em uma linha balanceada. Por fim, as soluções provenientes de ambas estratégias (para média e para o desvio-padrão) definem parâmetros de um modelo de simulação estocástico que também foi desenvolvido neste trabalho e é apresentado na seção 4.2 .

\subsection{Modelo de simulação}

O objetivo do modelo de simulação é utilizar as soluções geradas pelas estratégias apresentadas na Seção 4.1, que consideram a integralidade das tarefas, para avaliar se é possível obter uma melhora na cadência da linha de produção com as soluções desbalanceadas. Nesta seção são apresentados os dois principais mecanismos de controle existentes no modelo detalhado nesta seção e o Apêndice A apresenta alguns detalhes de implementação e considerações sobre o modelo desenvolvido.

A variável a ser analisada para comparar a eficiência dos balanceamentos é o tempo total de simulação necessário para se completar a produção de um número determinado de itens. A linha modelada é serial, não-ritmada e sem buffers entre as estações. Também, assume-se que sempre há um produto disponível para a primeira estação e a última estação nunca é bloqueada. Considerando essas características, confeccionou-se um modelo seguindo a abordagem de eventos discretos cujos eventos disparados sinalizam a finalização do trabalho de uma estação. Ou seja, quando um evento é disparado existe a intenção de se passar uma peça (a parte terminada do trabalho) da estação atual para a seguinte. A Figura 10 mostra as transições de estado que controlam o comportamento de cada estação.

Cada estação, em um dado instante de tempo, encontra-se em um dos seguintes estados: LIVRE, OCUPADA ou BLOQUEADA. O estado LIVRE denota que a estação não está realizando nenhum trabalho e pode receber novas peças para processar, isto é, ela está aguardando a finalização do processo da estação precedente. Caso a primeira estação esteja LIVRE, ela troca, automaticamente, seu estado para OCUPADA (a primeira estação sempre tem um produto disponível). O estado OCUPADA indica que a estação está processando uma peça; quando esse processamento é finalizado, a estação verifica o estado 
da estação seguinte; se ele for LIVRE, então o produto é passado para a estação seguinte, caso seja OCUPADA, a estação atual modifica seu estado para BLOQUEADA, indicando que a estação está parada, aguardando a estação seguinte terminar seu trabalho. Se a estação atual for a última da linha, então ela não pode ficar BLOQUEADA e seu estado é alterado para LIVRE.

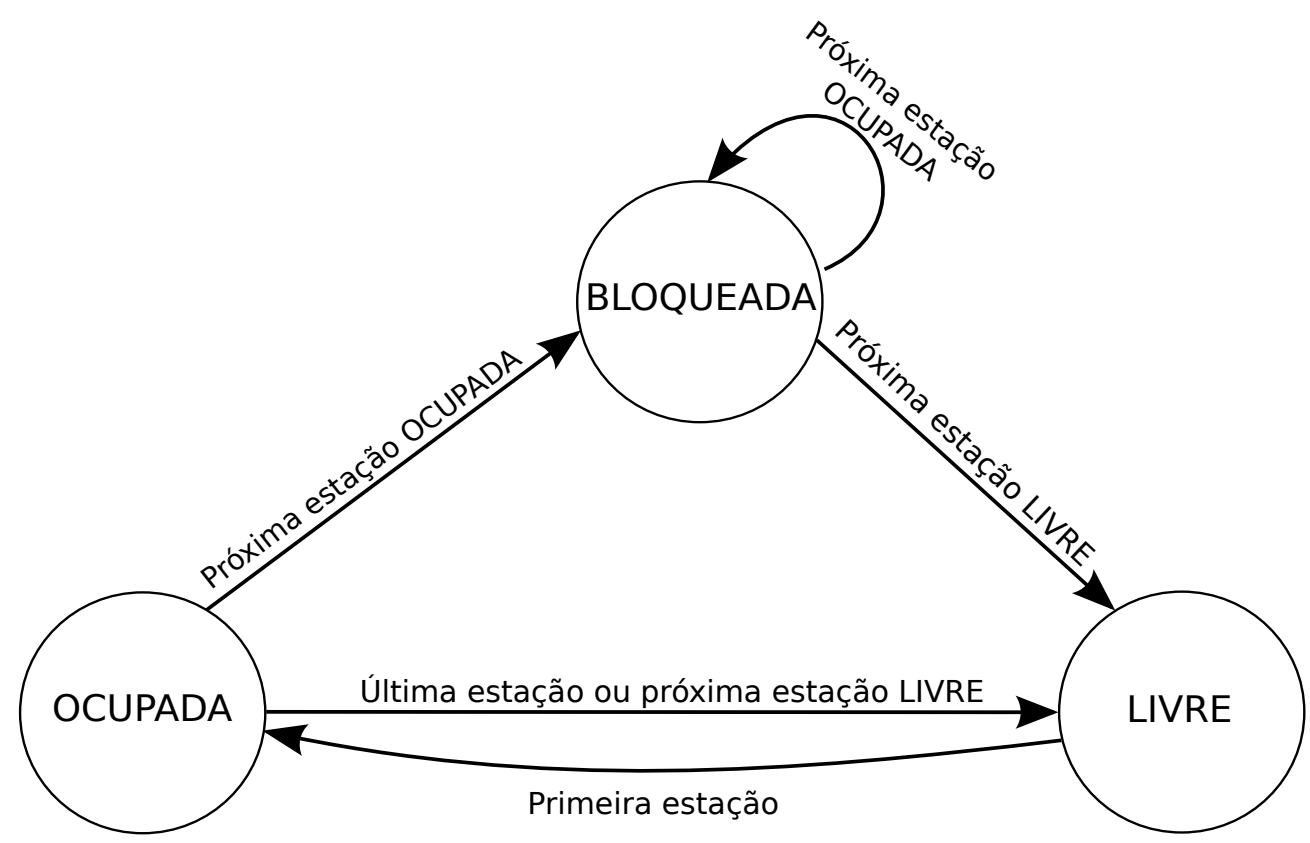

Figura 10 - Máquina de estados simplificada para as estações de trabalho. Quando uma estação está realizando algum trabalho seu estado é OCUPADA; no estado BLOQUEADA, ela está esperando a estação seguinte finalizar seu trabalho; e no estado LIVRE a estação está esperando a anterior enviar algum produto.

Durante a simulação, além do evento de início, só existe um tipo de evento: quando o trabalho de uma estação é finalizado, um evento previamente agendado é disparado e é feita a tentativa de se alterar o estado de uma estação de LIVRE para OCUPADA. Trata-se de um evento condicional, pois essa transição somente pode ocorrer caso a estação para qual se deseja entregar a peça esteja LIVRE. O agendamento de tal evento é realizado quando ocorre a transição de LIVRE para OCUPADA em uma estação. É nesse momento, também, que são amostrados os tempos estocásticos de cada tarefa na estação correspondente. Apenas com esse evento condicional, é possível controlar todo o fluxo da produção. Dessa forma, o mecanismo de três fases para simulação de eventos discretos (Figura 4) foi adaptado para o modelo de linhas de produção e está apresentado no fluxograma da Figura 11.

No início da simulação, todas as estações estão no estado LIVRE e o evento inicial é responsável por alterar o estado inicial da primeira estação para OCUPADA, nessa transição as tarefas alocadas à primeira estação têm seus tempos amostrados e a soma desses tempos define para quando o respectivo evento de finalização do processo é agendado. Em seguida, a simulação avança até o tempo do próximo evento na agenda e tenta-se enviar o 


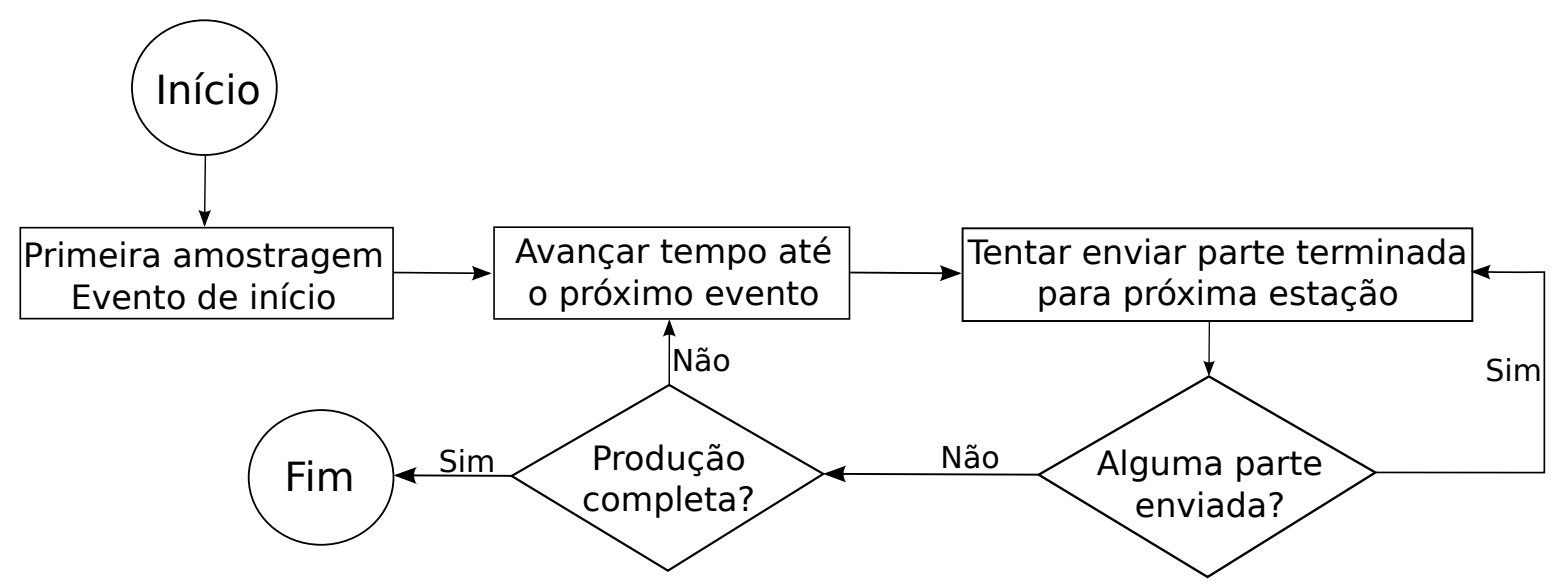

Figura 11 - Fluxograma de uma simulação. A simulação avança até o próximo evento agendado e tenta processar os eventos necessários. Se nenhum deles pode ser realizado, o tempo é novamente avançado até que pelo menos uma estação esteja livre. A simulação termina quando o número de produtos especificado é atingido.

produto da estação que agendou o evento em processamento para a estação seguinte. Se não for possível enviar, verifica-se a existência de alguma parte que possa ser enviada, isto é, se alguma estação mudou seu estado para LIVRE, permitindo, assim, o desbloqueio da estação anterior. Caso não haja uma estação passível de desbloqueio e o número de produtos a serem produzidos ainda não foi atingido, avança-se o tempo de simulação até o próximo evento até que seja possível dar continuidade ao fluxo de produtivo.

A alocação das tarefas às estações e, no caso do ALWABP, dos trabalhadores às estações é dada pelos modelos propostos anteriormente. As instâncias utilizadas para análise são as propostas em (OTTO; OTTO; SCHOLL, 2013) e (CHAVES; LORENA; MIRALLES, 2009) para SALBP e ALWABP, respectivamente. Dessa forma, com o modelo de programação inteira mista e o modelo de simulação estocástica, foi possível obter os resultados apresentados no Capítulo 5. 


\section{Experimentos computacionais}

Este capítulo discorre sobre a organização dos experimentos com a finalidade de explorar as questões de pesquisa e as consequências de se considerar a integralidade das tarefas no contexto do efeito Tigela. A Seção 5.1 apresenta quais são e como foram definidos os parâmetros dos experimentos para a geração dos resultados exibidos na Seção 5.2. Esses resultados foram obtidos com a resolução dos modelos de programação inteira mista e de simulação em um computador Intel Core is com 3 GB de memória RAM e sistema operacional Linux Ubuntu 12.10. Para a solução dos modelos de programação matemática foi utilizado o pacote computacional IBM ILOG CPLEX 12.5.0. As instâncias consideradas foram resolvidas até a otimalidade em questão de segundos. Além disso, os modelos de simulação também executam as 300 repetições desejadas em questão de segundos e detalhes sobre sua implementação podem ser encontrados no Apêndice A.

\subsection{Planejamento de experimentos}

Esta seção tem o objetivo de apresentar como os experimentos estão organizados de forma a gerar os resultados da Seção 5.2. Os cenários dos experimentos estão resumidos na Figura 12. Eles estão divididos em dois grupos: principais e complementares. Os experimentos principais exploram diretamente as questões de pesquisa e os experimentos complementares têm o objetivo de explicitar algumas diferenças de se considerar tarefas inteiras em relação ao que é usualmente feito na literatura.

Os experimentos principais se utilizam de instâncias do SALBP e ALWABP para a geração de resultados, que têm o objetivo de explorar configurações com o perfil de carga no formato de tigela para a média e desvio-padrão. Por outro lado, os experimentos complementares investigam o efeito Tigela apenas relacionado à média dos tempos das tarefas em instâncias do SALBP. Todos os experimentos consideram uma distribuição probabilística Normal para os tempos das tarefas. Os detalhes dos experimentos principais e complementares são apresentados nas subseções 5.1 .1 e 5.1.2, respectivamente. 


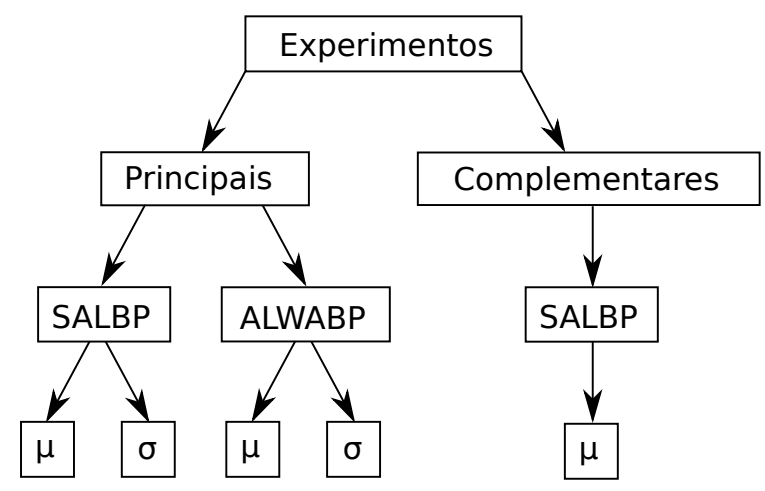

Figura 12 - Esquema representando os cenários dos experimentos realizados. Os experimentos principais investigam o SALBP e o ALWABP e, para cada um, o efeito Tigela relativo à média, $\mu$, e ao desviopadrão, $\sigma$. Os experimentos complementares utilizam apenas o SALBP e o efeito em relação à média para geração dos resultados desejados.

\subsubsection{Experimentos principais}

Esquematicamente, a solução completa para análise de alocações do tipo tigela, considerando a integralidade das tarefas, é ilustrada na Figura 8. Inicialmente, são fornecidos as tarefas, o grafo de precedências e os trabalhadores (no caso do ALWABP) ao modelo de programação inteira mista específico. Após a obtenção da solução ótima para a instância em questão, tem-se um balanceamento que favorece estações centrais com carga reduzida em relação às extremas. Esse balanceamento é utilizado para gerar alocações estocásticas para o modelo de simulação. Para isso, considera-se que o tempo de cada tarefa alocada pela etapa anterior segue uma distribuição Normal cuja média é o tempo determinístico da tarefa e o desvio-padrão depende do objetivo do experimento. Então, o modelo de simulação considera as características da linha para determinar o tempo necessário para produzir 100 itens, após a produção do item de número 50 (descartando a produção durante o período de warm-up). Isto é, os primeiros 50 produtos são produzidos para garantir que a linha esteja em regime permanente e, então, anota-se o tempo para a produção dos 100 itens seguintes. Essa análise de regime permanente foi feita utilizando-se o método gráfico de Welch como descrito em (MAHAJAN; INGALLS, 2004). Em linhas gerais, o método consiste em avaliar o gráfico de número de itens produzidos pelo tempo de saída do próximo item e determinar a partir de qual item pode-se considerar uma convergência. Por exemplo, a Figura 13 é relativa a uma das instâncias testadas nesse trabalho e representa uma situação típica. Para esse caso, pode-se verificar que a convergência ocorre antes da produção do vigésimo item.

Utilizando esse esquema, são definidos experimentos para avaliar desbalanceamentos em relação à média e ao desvio-padrão. Primeiramente, o conjunto de problemas a ser usado como benchmark é um subconjunto de 346 problemas de pequeno e médio porte propostos em (OTTO; OTTO; SCHOLL, 2013). Mais especificamente, foram escolhidos aqueles nos quais o limitante superior do número de estações não excede sete (e este limitante é usado como número de estações para a instância). OTTO; OTTO; SCHOLL (2013) ar- 


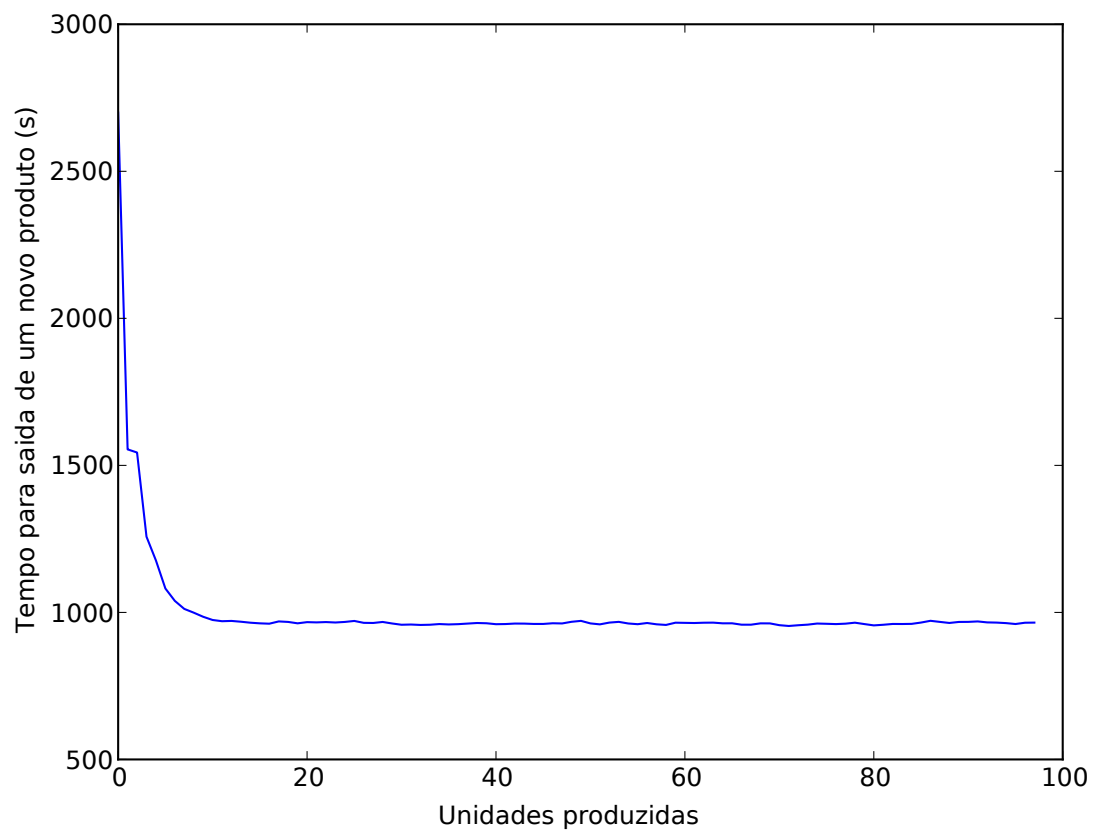

Figura 13 - Análise de regime permanente. Pode-se notar, pelo gráfico, que antes da produção do vigésimo item a linha já pode ser considerada em regime permanente. Neste trabalho, escolheu-se o limite de 50 unidades, de forma a garantir a operação em regime permanente para todas as instâncias consideradas. Também, nos casos considerados o regime permanente é atingido de forma relativamente rápida, pois não há buffers entre as estações.

gumentam que os benchmarks anteriores para problemas de balanceamento de linhas de produção possuem limitações, especialmente no que diz respeito à baixa representatividade dos conjuntos de problemas, dificultando generalizações das conclusões obtidas. As instâncias propostas por OTTO; OTTO; SCHOLL (2013) foram obtidas a partir de pesquisas em linhas de produção reais e de entrevistas com especialistas e podem ser agrupadas em características relacionadas à estrutura do grafo de precedências e à distribuição dos tempos das tarefas. O grafo de precedências é dividido em: gargalo (bottleneck), encadeado (chain) ou misto; grafos do tipo gargalo têm nós com um alto grau de entrada, grafos do tipo encadeado possuem tarefas encadeadas formando um caminho único e os grafos mistos não possuem uma estrutura predominante. Com relação à distribuição dos tempos das tarefas, as instâncias podem ser divididas em: peak at the bottom, peak in the middle ou bimodal; as instâncias peak at the bottom possuem muitas tarefas pequenas, as peak in the middle têm a maioria de tarefas de tamanho médio e as bimodais possuem muitas tarefas pequenas e grandes e um número limitado de tarefas de tamanho médio.

Para o ALWABP, as instâncias utilizadas fazem parte dos problemas em (CHAVES; LORENA; MIRALLES, 2009): as famílias Heskia e Roszieg. Esse conjunto é menos representativo se comparado ao proposto por OTTO; OTTO; SCHOLL (2013). Eles são classificados de acordo com dois critérios: variabilidade entre os trabalhadores, isto é, o quão diferente são os trabalhadores a serem alocados; e de acordo com a incompatibilidade entre tarefas 
e trabalhadores, isto é, a porcentagem de tarefas, em média, que um dado trabalhador não consegue executar. As famílias Roszieg e Heskia possuem 40 problemas de cada classe, ou seja, um total de 80 exemplares para cada uma das quatro classes testadas. Esses problemas se originam das famílias Heskia e Roszieg para o SALBP cujos tempos de tarefas para cada trabalhador podem ser gerados de duas formas: seja $t_{i}$ o tempo original da tarefa $i$; o tempo da tarefa para os demais trabalhadores é gerado aleatoriamente no intervalo $\left[1, t_{i}\right]$ para instâncias com baixa variabilidade entre os trabalhadores e entre $\left[1,3 t_{i}\right]$ para alta variabilidade. Em relação à incompatibilidade também há dois níveis: baixa (10\%) e alta (20\%).

Além dessas definições, para obtenção dos resultados apresentados na Seção 5.2, cada conjunto de parâmetros de entrada foi simulado 300 vezes e cada simulação dura o tempo necessário para uma produção de 100 unidades, após o warm-up. Também, foi utilizado um teste-t com limite (p-valor) de $5 \%$ para verificar a diferença estatística entre os experimentos relevantes, isto é, se houver uma chance menor do que $5 \%$ de as amostras serem equivalentes, então elas são consideradas como diferentes.

Após a definição da metodologia para os experimentos, são definidos os parâmetros dos modelos propostos para SALBP e ALWABP com objetivo de analisar desbalanceamentos da média e do desvio-padrão. Para a média, experimentos foram realizados com os parâmetros $\alpha_{1}=1$ e $\beta \in B=\{1,00 ; 0,99 ; 0,98 ; 0,97 ; 0,96 ; 0,95 ; 0,94\}$, como definidos nas relações (17) e (18). Assim como para avaliar desbalanceamentos em relação ao desvio-padrão, os experimentos foram realizados com $\theta \in\left\{\theta_{i}=\beta_{i} \mid \beta_{i} \in B\right\}$.

\subsubsection{Experimentos complementares}

Foram definidos, também, alguns experimentos complementares. Eles são complementares no sentido de não atacarem diretamente as questões de pesquisa definidas na Seção 1.1, porém têm potencial para explicitar diferenças ao se considerar a indivisibilidade das tarefas para o efeito Tigela em relação ao usualmente considerado na literatura e, consequentemente, dar suporte e motivação à investigação do tema.

Especificamente, o objetivo desses experimentos complementares é comparar as alocações geradas pelos modelos modificados do SALBP (restrições (15)) com alocações "distorcidas", que foram definidas a partir das instâncias originais mas possuem uma semelhança maior com uma "tigela". Os modelos modificados induzem a uma alocação com a forma de tigela, no entanto, dada a restrição de se ter tarefas inteiras, situações como a mostrada na Figura 14 podem ocorrer.

A premissa básica para se poder comparar duas alocações é que a carga de trabalho total da linha seja igual. Com isso, foram construídos dois métodos para geração de alocações distorcidas. O primeiro consiste em distribuir a carga total de trabalho relaxando a restrição de integralidade das tarefas. Em outras palavras, esse método pode ser comparado aos trabalhos citados no Capítulo 3. O segundo consiste em alterar, individualmente, 


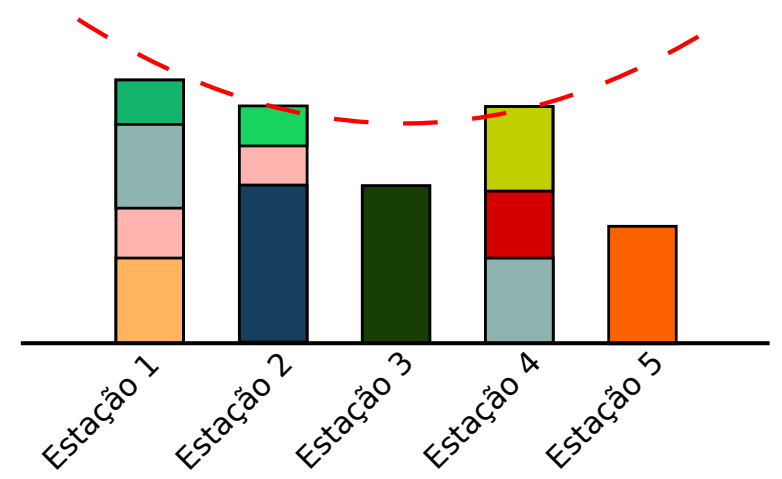

Figura 14 - A linha tracejada mostra o que seria uma alocação tigela ideal e os quadrilatéros representam as tarefas indivisíveis. Para este exemplo, as estações 2 e 4 têm a carga "ideal" e as demais estações têm cargas menores. Note que essa situação não viola as restrições do modelo modificado para o SALBP.

as tarefas em cada estação de forma a se obter uma tigela ideal, mantendo a mesma carga de trabalho.

De outra forma, o primeiro método é equivalente a preencher a carga das estações com apenas uma tarefa de tamanho adequado, portanto será referido daqui em diante como método de encaixe unitário. O primeiro passo desse método consiste em calcular a carga balanceada para cada estação desconsiderando a integralidade, que, mantendo a notação definida para o modelo do SALBP (Seção 2.1.1), é dada por:

$$
C_{b a l}=\frac{\sum_{i \in N} t_{i}}{|S|}
$$

Ou seja, apenas se distribui a carga total da instância, $\sum_{i \in N} t_{i}$, igualmente para todas as estações. Então, a carga balanceada $C_{b a l}$ é multiplicada pelo fator $\alpha_{k}, k \in S$, obedecendo as equações (17) e (18), definidas anteriormente. Neste ponto tem-se um perfil de carga, dependente dos parâmetros $\alpha_{1}$ e $\beta$. Por fim, é somado um fator constante à carga de todas as estações de forma a se obter a mesma carga da instância original. Portanto, cada estação tem a carga determinística, dada por:

$$
W_{k}=\alpha_{k} C_{b a l}+\left(C_{b a l}-\frac{\sum_{k \in S} \alpha_{k} C_{b a l}}{|S|}\right), \quad \forall k \in S
$$

Note que $\sum_{k \in S} W_{k}=|S| C_{b a l}=\sum_{i \in N} t_{i}$, ou seja, essa transformação de cargas mantém constante a carga total da instância. Foram escolhidos valores de $\alpha_{1}=1$ e $\beta \in B$, assim como nos demais experimentos para geração dos resultados. Dessa forma, são geradas as alocações a serem simuladas do método de encaixe unitário.

O segundo método consiste em modificar um balanceamento fornecido pelo modelo modificado do SALBP para que ele se ajuste melhor a uma tigela. Isso é feito multiplicando-se cada uma das tarefas em cada estação por um fator que faz com que a carga total da estação torne-se a desejada, por essa razão esse método foi denominado encaixe múltiplo. Para isso, o primeiro passo, após obtida a alocação determinada pelo modelo de programação inteira mista, é determinar a carga desejada para cada estação. Isso pode 
ser feito utilizando a equação (28). Então, a nova carga determinística correspondente a cada tarefa $i$ na estação $k, t_{i k}$, é dada por:

$$
t_{i k}=\tilde{t}_{i k} \cdot \frac{W_{k}}{\sum_{i \in k} \tilde{t}_{i k}}, \quad \forall i \in k, \forall k \in S
$$

sendo que, $\tilde{t}_{i k}$ representa o tempo original da tarefa $i$ na estação $k$, isto é, está relacionado com a alocação dada pelo modelo modificado. Para esse caso também foram gerados resultados para os valores de $\alpha_{1}=1$ e $\beta \in B$.

Assim, são realizadas simulações e avaliados os tempos para produção de 100 itens, em regime permanente, para os três cenários: os dois métodos descritos nesta seção e o da Seção 5.1.1. Verifica-se qual a profundidade de tigela tem o melhor desempenho e, em seguida, o melhor desempenho entre três métodos é determinado. Esse procedimento é realizado considerando dois coeficientes de variação: 0,1 e 0,2 e, assim, tem-se a Tabela 10 comparando essas abordagens.

É importante destacar que existem diversas maneiras de gerar novas alocações que sigam um perfil de tigela. Os dois métodos aqui reportados são apenas duas possibilidades e têm o propósito de explicitar a diferença entre considerar a indivisibilidade das tarefas ou utilizar a abordagem usual da literatura acerca do efeito Tigela.

\subsection{Resultados}

Os resultados apresentados nesta seção foram obtidos de acordo com o apresentado na Seção 5.1 e utilizando um método de Monte Carlo. As tabelas de 2 a 9 são relativas aos experimentos principais, sendo que as tabelas de 2 a 7 contêm resultados referentes ao SALBP, as tabelas 8 e 9 estão relacionadas ao ALWABP e a Tabela 10 é referente aos experimentos complementares. Os resultados para o SALBP são mais detalhados, pois acredita-se que as instâncias são mais representativas estatisticamente, ampliando o poder de generalização e aumentando a confiabilidade dos resultados. Todas as tabelas relativas aos experimentos principais apresentam o número total de instâncias da classe considerada, a fração das instâncias em que foi possível observar o efeito Tigela (isto é, houve melhora em alguma alocação desbalanceada em relação à perfeitamente balanceada) e o respectivo coeficiente de variação (c.v. - razão entre desvio-padrão e média de cada tarefa em uma estação), $c_{s}, s \in S$. O símbolo "_" é usado para indicar que os resultados não se aplicam para a célula correspondente. A sigla BN (bottleneck) indica grafos com estrutura em gargalo, a sigla CH ( chain) representa grafos do tipo encadeado e expressão tarefas pequenas está relacionada à distribuição de tempos das tarefas peak at the bottom. Além disso, são apresentados $\beta_{\text {mean }}$ e $\theta_{\text {mean }}$, definidos como: 


$$
\begin{aligned}
& \beta_{\text {mean }}=\frac{\sum_{b \in U} \beta^{*}(b)}{|U|}, \\
& \theta_{\text {mean }}=\frac{\sum_{b \in \tilde{U}} \theta^{*}(b)}{|\tilde{U}|},
\end{aligned}
$$

sendo $U$ o conjunto de instâncias em que o efeito Tigela ocorreu para a média e $\beta^{*}(b)$ é o parâmetro $\beta \in B$ que apresentou o melhor desempenho para instância $b$ nos experimentos relacionados à média. Analogamente, $\tilde{U}$ denota o conjunto de instâncias em que o efeito Tigela ocorreu para o desvio-padrão e $\theta^{*}(b)$ representa o parâmetro $\theta \in B$ ótimo para $b$, entre os considerados nos experimentos correspondentes.

Para o SALBP, as tabelas 2, 3 e 4 resumem resultados dos experimentos para avaliação do desbalanceamento da média. A Tabela 2 apresenta os resultados agrupados por número de estações. A maioria das instâncias consideradas (163) possui três estações de trabalho na solução ótima e em quase $54 \%$ dos casos para coeficiente de variação 0,1 a alocação Tigela foi estatisticamente mais eficiente do que a solução balanceada, levando a um $\beta_{\text {mean }}=0,9781$. O menor $\beta_{\text {mean }}$ (maior profundidade de tigela) foi obtido para instâncias com quatro estações e coeficiente de variação 0,2. Este também foi o caso que apresentou, relativamente, o maior número de instâncias nas quais as alocações com efeito Tigela conseguiram resultados estatisticamente mais eficientes $(92,11 \%)$.

Tabela 2 - Resultados de desbalanceamento da média para instâncias SALBP agrupados por número de estações.

\begin{tabular}{|c|c|c|c|c|c|c|}
\hline & \multicolumn{5}{|c|}{ Estações } & \\
\hline & $\mathbf{3}$ & $\mathbf{4}$ & $\mathbf{5}$ & $\mathbf{6}$ & $\mathbf{7}$ & \\
\hline Instâncias & 163 & 38 & 89 & 50 & 6 & \multirow{2}{*}{$\mathbf{c . v .}$} \\
\hline Ocorrência & 0,5399 & 0,8421 & 0,7416 & 0,7800 & 0,8333 & \multirow{2}{*}{$\mathbf{0 , 1}$} \\
\cline { 1 - 6 }$\beta_{\text {mean }}$ & 0,9781 & 0,9781 & 0,9788 & 0,9777 & 0,9900 & \\
\hline Ocorrência & 0,6624 & 0,9211 & 0,8202 & 0,8800 & 0,6667 & \multirow{2}{*}{$\mathbf{0 , 2}$} \\
\cline { 1 - 5 }$\beta_{\text {mean }}$ & 0,9679 & 0,9629 & 0,9684 & 0,9695 & 0,9800 & \\
\hline
\end{tabular}

A Tabela 3 resume os resultados agrupados pela estrutura do grafo e pela distribuição dos tempos das tarefas. Para o grupo de estrutura do grafo, a maior profundidade de tigela foi encontrada para a classe misto com coeficiente de variação 0,2 , enquanto que a classe encadeado, para o mesmo c.v., apresentou a maior fração de instâncias nas quais é vantajoso induzir um desbalanceamento na carga. Também com c.v. de 0,2, a distribuição de tempos de tarefa tarefas pequenas apresentou maior profundidade média e o maior número relativo de instâncias favoráveis ao efeito Tigela ocorreu na classe bimodal. Além disso, é possível observar que grafos com estrutura encadeada e distribuição bimodal parecem favorecer a ocorrência do fenômeno Tigela para ambos coeficientes de variação considerados.

A Tabela 4 apresenta resultados combinando o número de estações com a estrutura do grafo e com a distribuição dos tempos das tarefas. Em alguns desses casos não há 
Tabela 3 - Resultados de desbalanceamento da média para instâncias SALBP agrupados por estrutura do grafo de precedências e distribuição do tempo de execução das tarefas.

\begin{tabular}{|c|c|c|c|c|c|c|}
\hline & \multicolumn{3}{|c|}{ Estrutura do grafo } & \multicolumn{2}{c|}{$\begin{array}{r}\text { Distribuição do } \\
\text { tempo de execução }\end{array}$} & \\
\hline & BN & CH & Misto & Bimodal & Tarefas pequenas & \\
\hline Instâncias & 98 & 99 & 149 & 174 & 172 & c.v. \\
\hline Ocorrência & 0,6531 & 0,6970 & 0,6510 & 0,7644 & 0,5640 & \multirow{2}{*}{$\mathbf{1}$} \\
\hline$\beta_{\text {mean }}$ & 0,9820 & 0,9781 & 0,9764 & 0,9788 & 0,9780 & \\
\hline Ocorrência & 0,7857 & 0,8182 & 0,7114 & 0,8448 & 0,6802 & \multirow{2}{*}{$\mathbf{2}$} \\
\hline$\beta_{\text {mean }}$ & 0,9682 & 0,9683 & 0,9672 & 0,9682 & 0,9674 & \\
\hline
\end{tabular}

instâncias: três estações com distribuição bimodal e cinco estações com muitas tarefas pequenas, por exemplo. Novamente, para instâncias com três e quatro estações, é possível observar que um grafo de precedências encadeado induz uma grande taxa de ocorrência do efeito Tigela. Note que é difícil tecer conclusões para instâncias com sete estações visto que elas aparecem em um número reduzido. Da mesma forma, o número de instâncias nas classes de distribuição dos tempos não é adequado para comparação de resultados entre distribuição bimodal e tarefas pequenas.

As tabelas 5, 6 e 7 apresentam os resultados referentes a perfis de tigela do coeficiente de variação $c_{s}, s \in S$. De certa forma, esses resultados são mais previsíveis que os relativos à média dado que não há restrição de integralidade. Por outro lado, eles permitem corroborar as pesquisas sobre ser vantajoso sobrecarregar estações com uma menor variabilidade e avaliar a robustez do efeito Tigela para esse caso.

A Tabela 5 mostra os resultados agrupados por número de estações. Para o coeficiente de variação 0,2 , o fenômeno Tigela foi observado em todas as instâncias, com exceção do grupo com três estações, no qual o efeito foi observado em 77,30\% das instâncias, com $\theta_{\text {mean }}=0,9466$. Além disso, para os grupos de seis e sete estações, e coeficiente de variação de 0,2 , o parâmetro $\theta_{\text {mean }}$ atingiu o mínimo considerado nos experimentos.

A Tabela 6 resume os resultados agrupados por estrutura do grafo e distribuição dos tempos das tarefas. No grupo de estrutura do grafo, as maiores profundidades médias de tigela ocorreram nas classes encadeado e misto com c.v. de 0,2 e a classe que apresentou o maior número relativo de instâncias em que o efeito ocorreu foi a misto. A distribuição dos tempos bimodal apresentou a tigela média mais profunda e o maior número de instâncias com o fenômeno. Todas as classes tiveram uma taxa de ocorrência do efeito de mais de $75 \%$, atingindo $100 \%$ na classe bimodal com coeficiente de variação de 0,2 .

A Tabela 7 mostra resultados combinando número de estações com estrutura do grafo ou distribuição dos tempos das tarefas para análise de desbalanceamento na variabilidade das tarefas. Para instâncias com três estações, o fenômeno foi estatisticamente significante em mais de $50 \%$ dos casos. Para instâncias com mais de três estações, o efeito foi observado em quase todos os casos e a profundidade máxima da tigela foi atingida frequentemente.

Com relação ao ALWABP, a Tabela 8 apresenta os resultados agrupados por varia- 
Tabela 4 - Resultados de desbalanceamento da média para instâncias SALBP combinando número de estações com estrutura do grafo de precedências ou distribuição do tempo de execução das tarefas.

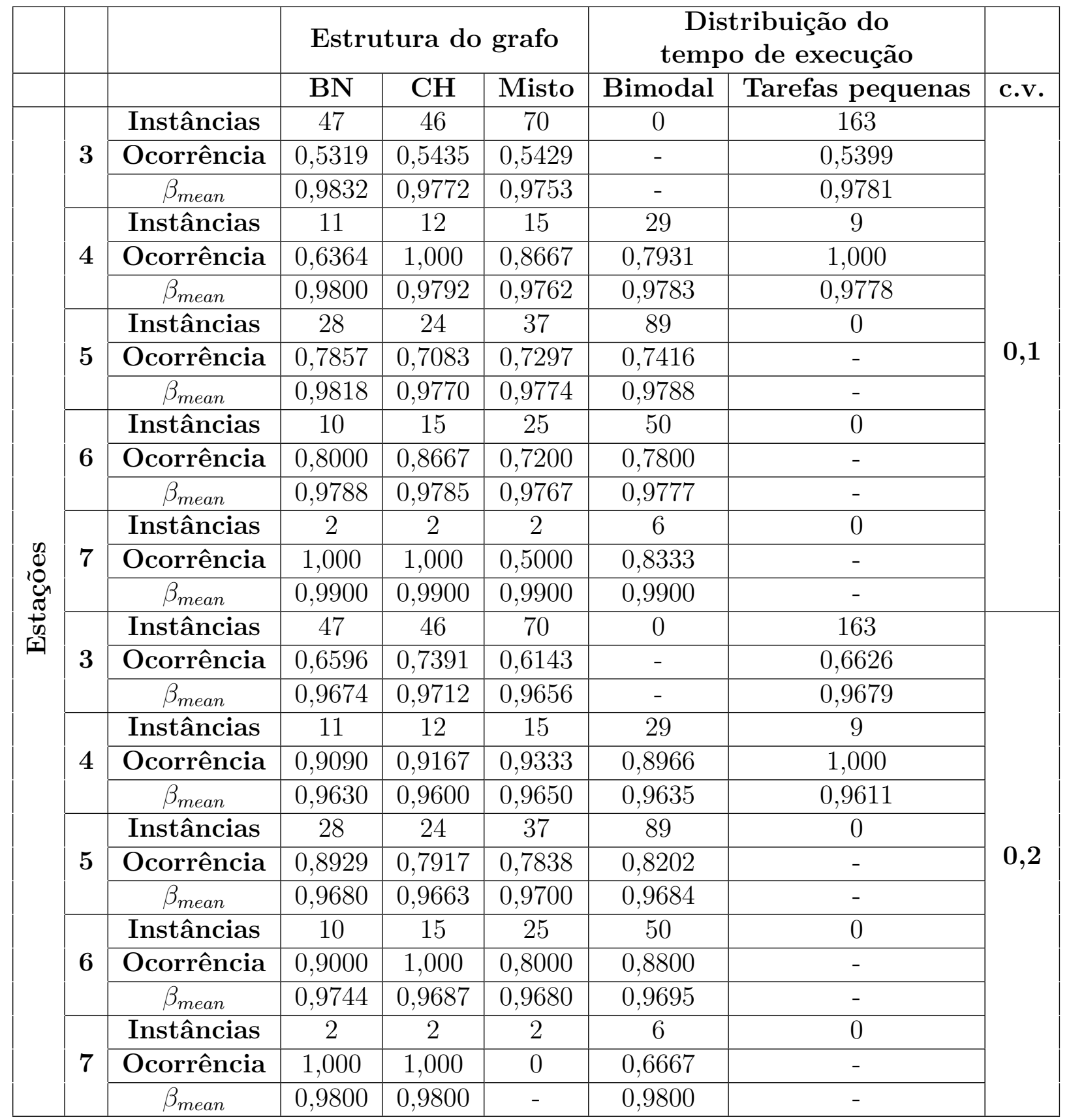

bilidade em relação aos trabalhadores: baixa variabilidade significa que os tempos para uma mesma tarefa variam pouco entre um trabalhador e outro e uma variabilidade alta denota grande heterogeneidade no conjunto de trabalhadores, de acordo com o definido na Seção 5.1. Assim como no caso do SALBP, o coeficiente de variação maior favoreceu o efeito. Para a média, as instâncias com alta variabilidade apresentaram uma maior ocorrência do efeito, enquanto que, para o desvio-padrão, houve um relativo equilíbrio na ocorrência.

A Tabela 9, por sua vez, apresenta os resultados para o ALWABP em relação a incompatibilidade entre tarefa e trabalhador: uma incompatibilidade baixa significa que há 
Tabela 5 - Resultados de desbalanceamento de desvio-padrão para instâncias SALBP agrupados por número de estações.

\begin{tabular}{|c|c|c|c|c|c|c|}
\hline & \multicolumn{5}{|c|}{ Estações } & \\
\hline & $\mathbf{3}$ & $\mathbf{4}$ & $\mathbf{5}$ & $\mathbf{6}$ & $\mathbf{7}$ & \\
\hline Instâncias & 163 & 38 & 89 & 50 & 6 & \multirow{2}{*}{$\mathbf{c . v .}$} \\
\hline Ocorrência & 0,5337 & 0,9737 & 1,000 & 1,000 & 1,000 & \multirow{2}{*}{$\mathbf{0 , 1}$} \\
\hline$\theta_{\text {mean }}$ & 0,9480 & 0,9462 & 0,9420 & 0,9410 & 0,9400 & \\
\hline Ocorrência & 0,7730 & 1,000 & 1,000 & 1,000 & 1,000 & \multirow{2}{*}{$\mathbf{0}, \mathbf{2}$} \\
\hline$\theta_{\text {mean }}$ & 0,9466 & 0,9450 & 0,9409 & 0,9400 & 0,9400 & \\
\hline
\end{tabular}

Tabela 6 - Resultados de desbalanceamento de desvio-padrão para instâncias SALBP agrupados por estrutura do grafo de precedências e distribuição do tempo de execução das tarefas.

\begin{tabular}{|c|c|c|c|c|c|c|}
\hline & \multicolumn{2}{|c|}{ Estrutura do grafo } & \multicolumn{2}{c|}{$\begin{array}{r}\text { Distribuição do } \\
\text { tempo de execução }\end{array}$} & \\
\hline & BN & CH & Misto & Bimodal & Tarefas pequenas & \\
\hline Instâncias & 98 & 99 & 149 & 174 & 175 & c.v. \\
\hline Ocorrência & 0,7653 & 0,8080 & 0,7651 & 0,9943 & 0,5581 & \multirow{2}{*}{$\mathbf{0 , 1}$} \\
\hline$\theta_{\text {mean }}$ & 0,9437 & 0,9446 & 0,9445 & 0,9424 & 0,9478 & \\
\hline Ocorrência & 0,8776 & 0,8788 & 0,9128 & 1,000 & 0,7849 & \multirow{2}{*}{$\mathbf{0} \mathbf{2}$} \\
\hline$\theta_{\text {mean }}$ & 0,9429 & 0,9438 & 0,9438 & 0,9415 & 0,9462 & \\
\hline
\end{tabular}

poucas tarefas, em média, que um trabalhador não pode executar, enquanto que uma incompatibilidade alta implica em um número maior de tarefas que não pode ser executado por um dado trabalhador. Os resultados são bem próximos aos mostrados na Tabela 8, o que sugere uma certa independência entre a ocorrência do efeito Tigela em relação às características consideradas, pelos menos para as famílias Heskia e Roszieg.

Com esses resultados dos experimentos principais (tabelas de 2 a 9), pode-se observar que os modelos determinísticos de programação inteira mista foram capazes de gerar balanceamentos para linhas de produção estocástica com potencial para explorar o fenômeno Tigela. Para o ALWABP, também foi possível observar o efeito na maioria dos casos (pelo menos 60\%), embora seja difícil dizer se há uma relação entre a ocorrência relativa do efeito e o tipo de problema (SALBP ou ALWABP), visto que as instâncias do ALWABP são menos representativas.

Por fim, a Tabela 10 apresenta resultados referentes aos experimentos complementares (Seção 5.1.2). Os resultados foram gerados para os coeficientes de variação de 0,1 e 0,2 para os três métodos de geração de alocação considerados: encaixe unitário, encaixe múltiplo e inteiro (método utilizado para a geração dos resultados apresentados nas tabelas de 2 a 9). Cada célula na tabela apresenta o número de instâncias em que o método foi melhor do que os demais, isto é, para cada instância foi comparado o tempo de produção de 100 itens da melhor profundidade de tigela entre cada um dos métodos.

Pode-se notar que o método de encaixe múltiplo produziu as melhores alocações. Enquanto que o método de encaixe unitário sempre perdeu para um dos outros dois 
Tabela 7 - Resultados de desbalanceamento de desvio-padrão para instâncias SALBP combinando número de estações com estrutura do grafo de precedências ou distribuição do tempo de execução das tarefas.

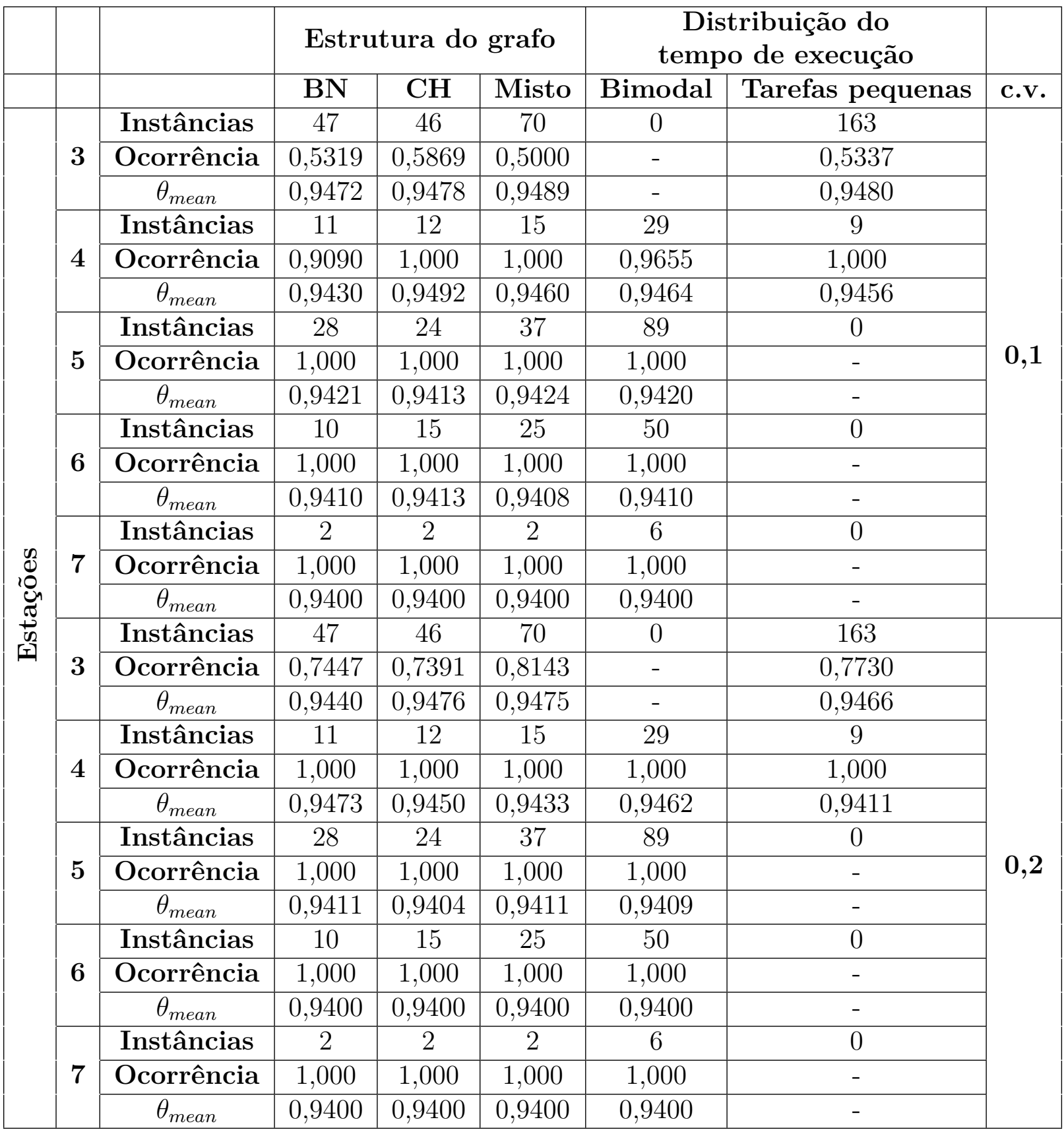

métodos. Isso pode ser explicado pelo fato do método de encaixe unitário gerar alocações em que as estações possuem uma variabilidade bem maior do que a dos demais métodos, que são razoavelmente equilibrados nesse quesito. Isso também indica que pode não ser adequado considerar as alocações utilizadas na literatura como uma tarefa em cada estação, preenchendo a carga necessária. Isso abre uma lacuna no que diz respeito a como relacionar as alocações previamente estudadas com alocações que consideram tarefas inteiras. Por exemplo, o coeficiente de variação de uma estação mencionado em diversos trabalhos da Seção 3 pode se referir ao coeficiente agregado de todas as tarefas. Nesse contexto, surgem algumas questões como: quais as consequências de se considerar um 
Tabela 8 - Resultados para desbalanceamento de média e desvio-padrão para instâncias ALWABP agrupados por variabilidade (baixa ou alta) dos tempos de execução das tarefas.

\begin{tabular}{|c|c|c|c|c|c|}
\hline & \multicolumn{2}{|r|}{ Baixa } & \multicolumn{2}{|r|}{ Alta } & \multirow[b]{2}{*}{ c.v. } \\
\hline & média & desvio-padrão & média & desvio-padrão & \\
\hline Ocorrência & 0,6125 & 0,8625 & 0,7500 & 0,8000 & \multirow{2}{*}{0,1} \\
\hline$\beta_{\text {mean }}$ ou $\theta_{\text {mean }}$ & 0,9684 & 0,9423 & 0,9670 & 0,9430 & \\
\hline Ocorrência & 0,6750 & 0,9625 & 0,7750 & 0,9500 & \multirow{2}{*}{0,2} \\
\hline$\beta_{\text {mean }}$ ou $\theta_{\text {mean }}$ & 0,9635 & 0,9426 & 0,9639 & 0,9424 & \\
\hline
\end{tabular}

Tabela 9 - Resultados para desbalanceamento de média e desvio-padrão para instâncias ALWABP agrupados por incompatibilidade (baixa ou alta) das tarefas em relação aos trabalhadores.

\begin{tabular}{|c|c|c|c|c|c|}
\hline & \multicolumn{2}{|r|}{ Baixa } & \multicolumn{2}{|r|}{ Alta } & \multirow[b]{2}{*}{ c.v. } \\
\hline & média & desvio-padrão & média & desvio-padrão & \\
\hline Ocorrência & 0,6500 & 0,8375 & 0,7125 & 0,8250 & \multirow{2}{*}{0,1} \\
\hline$\beta_{\text {mean }}$ ou $\theta_{\text {mean }}$ & 0,9702 & 0,9430 & 0,9653 & 0,9419 & \\
\hline Ocorrência & 0,6875 & 0,9750 & 0,7625 & 0,9375 & \multirow{2}{*}{0,2} \\
\hline$\beta_{\text {mean }}$ ou $\theta_{\text {mean }}$ & 0,9632 & 0,9426 & 0,9707 & 0,9424 & \\
\hline
\end{tabular}

Tabela 10 - Comparação entre os métodos de geração de alocações com o perfil de tigela. Cada célula contém o número de instâncias que obtiveram o melhor desempenho se comparadas com os outros métodos. Os experimentos foram realizados considerando dois coeficientes de variação.

\begin{tabular}{|c|c|c|}
\hline & \multicolumn{2}{|c|}{$\begin{array}{c}\text { Coeficiente } \\
\text { de variação }\end{array}$} \\
\hline Método & $\mathbf{0 , 1}$ & $\mathbf{0 , 2}$ \\
\hline Encaixe unitário & 0 & 0 \\
\hline Encaixe múltiplo & 263 & 245 \\
\hline Inteiro & 83 & 101 \\
\hline Total & $\mathbf{3 4 6}$ & $\mathbf{3 4 6}$ \\
\hline
\end{tabular}

c.v. igual para todas as tarefas? E se os coeficientes forem diferentes? Qual situação se adequa melhor a linhas de produção reais?

Também, os experimentos mostraram que o método inteiro se beneficiou mais do efeito Tigela do que os demais. Ao se considerar o percentual de aumento de desempenho relação ao caso perfeitamente balanceado, o método inteiro teve uma melhora média de 0,24\% contra $0,14 \%$ do encaixe múltiplo com c.v. de 0,1 e $0,37 \%$ contra $0,23 \%$ com c.v. de 0,2.

É importante mencionar, mais um vez, que os métodos de encaixe unitário e múltiplo apresentados aqui têm a finalidade, apenas, de aumentar o entendimento sobre a consideração de tarefas inteiras em linhas de produção não-ritmadas, salientando a diferença entre esse caso e o previamente estudado na literatura, que considera apenas a carga total de cada estação. 


\section{Conclusões e trabalhos futuros}

Linhas não-ritmadas possuem modelos estocásticos complexos e que, até o momento, só podem ser resolvidos analiticamente por aproximações ou para casos reduzidos e considerando hipóteses que podem estar distantes das situações encontradas na prática. Assim, na literatura, o estudo desses sistemas é comumente feito utilizando-se simulação.

Nessas linhas, o conhecido fenômeno Tigela faz com que se possam obter maiores taxas produtivas caso sejam introduzidos desbalanceamentos específicos na carga das estações. Este trabalho explora tal fenômeno. Especificamente, busca-se verificar se o fenômeno ocorre em linhas com características mais próximas da realidade do que as consideradas previamente na literatura, no que diz respeito à integralidade das tarefas. Além disso, procura-se determinar se há características em um problema de balanceamento que favoreçam o aparecimento do fenômeno e, também, se o problema de Designação de Trabalhadores e Balanceamento de Linhas de Produção (ALWABP) pode se beneficiar do efeito. Para isso, são propostos modelos determinísticos de programação inteira mista, derivados dos modelos para o SALBP e o ALWABP de linhas ritmadas, capazes de induzir uma alocação de tarefas com o perfil Tigela que, por sua vez, é utilizada como entrada de um modelo de simulação estocástico para linhas não-ritmadas e estocásticas. É importante destacar que não foi encontrado na literatura nenhum estudo do efeito Tigela considerando a indivisibilidade das tarefas, o que é considerado para os modelos propostos através dos problemas de teste para o SALBP e o ALWABP propostos em (OTTO; OTTO; SCHOLL, 2013) e (CHAVES; LORENA; MIRALLES, 2009), respectivamente.

Em linhas gerais, os resultados obtidos permitiram responder às questões de pesquisa da seguinte forma: o fenômeno Tigela pode ter aplicações práticas ou seus efeitos são observáveis apenas na teoria? Existe potencial para que o fenômeno seja explorado em aplicações mais próximas às encontradas na prática, pois os modelos modificados, tanto do SALBP quanto do ALWABP, geraram soluções capazes de se beneficiar do efeito Tigela. Ainda, como as instâncias do SALBP utilizadas para essa avaliação são mais gerais que às apresentadas em estudos anteriores, acredita-se que isso argumenta em favor da generalização das conclusões obtidas. Existe alguma característica dos problemas de ba- 
lanceamento de linhas de produção que favorece o aparecimento do efeito Tigela? Dentre as consideradas nos experimentos, não foi possível detectar nenhuma que (des)favoreça particularmente o aparecimento do efeito. O problema de balanceamento de linhas de produção e designação de trabalhadores pode se beneficiar do efeito Tigela? Os resultados obtidos foram semelhantes aos do SALBP, no entanto é importante destacar que a reduzida diversidade das instâncias do ALWABP pode dificultar a generalização de conclusões feitas para esse caso.

Além da exploração direta das questões de pesquisa, foram realizados experimentos cujos resultados sugerem que considerar a indivisibilidade das tarefas leva a questões que previamente não eram explícitas, tais como: quais as diferenças entre se considerar coeficientes de variação iguais para todas as tarefas e coeficientes diferentes? Qual situação é mais adequada para que tipo de linha de produção? Quais as implicações dessas diferenças para os problemas de balanceamento?

Também podem ser consideradas contribuições, as alterações nos modelos do SALBP e ALWABP, passíveis de adaptações para induzir alocações com outros formatos como tigela invertida, crescente, descrescente e estações lentas e rápidas alternadas, além do tigela utilizado no estudo. Essas alterações nos modelos também podem ser estendidas para outros problemas de balanceamento de linhas de produção, assim como as estratégias para geração de tigelas de diferentes profundidades tanto para a média quanto para o desvio padrão.

Portanto, acredita-se que o trabalho apresentado nesse documento contribui para o entendimento e exploração do fenômeno Tigela em linhas de produção. Além disso, a partir deste trabalho, algumas outras questões podem ser exploradas.

Linhas futuras de trabalho incluem a investigação de outros padrões de alocação de carga, além do tigela, e o uso de técnicas de programação estocástica para buscar pela alocação ótima para as versões estocásticas dos problemas de balanceamento aqui estudados. Também, podem ser exploradas questões relacionadas às tarefas em si: as tarefas podem seguir distribuições probabilísticas diferentes ou terem coeficientes de variação distintos. Ainda, pode ser feita uma análise mais minuciosa para buscar características dos problemas de balanceamento que favoreçam a exploração do efeito Tigela e a própria exploração de outros problemas de balanceamento como linhas com buffers, com estações paralelas e linhas multi-modelo. 


\section{Referências}

AQLAN, F.; LAM, S. S.; RAMAKRISHNAN, S. An integrated simulation-optimization study for consolidating production lines in a configure-to-order production environment. International Journal of Production Economics. Elsevier, v. 148, p. 51-61, fev. 2014.

BARTEN, K. A queuing simulator for determining optimum invetory levels in a sequential process. Journal of Industrial Engineering. v. 14, n. 6, p. 703-710, 1962.

BATTAÏA, O.; DOLGUI, A. A taxonomy of line balancing problems and their solution approaches. International Journal of Production Economics. v. 142, n. 2, p. 259-277, 2013.

BERNARD, C.; BOYLE, P. Monte Carlo methods for pricing discrete Parisian options. The European Journal of Finance. v. 17, n. 3, p. 169-196, 2011.

BOYSEN, N.; FLIEDNER, M.; SCHOLL, A. A classification of assembly line balancing problems. European Journal of Operational Research. v. 183, n. 2, p. 674-693, dez. 2007.

BRUNET, R. et al. Hybrid simulation-optimization based approach for the optimal design of single-product biotechnological processes. Computers \& Chemical Engineering. Elsevier Ltd, v. 37, p. 125-135, fev. 2012.

ChaveS, A. A.; LOREnA, L. A. N.; MIRAlleS, C. Hybrid Metaheuristic for the Assembly Line Worker Assignment and Balancing Problem. In: 6th International Workshop, HM 2009. Undine, Italy: Springer Berlin Heidelberg, 2009. p. 1-14.

CHECKLAND, P. Systems Thinking, Systems Practice. John Wiley \& Sons, Ltd, 1981.

DAS, B. et al. A computer simulation approach to evaluating bowl versus inverted bowl assembly line arrangement with variable operation times. The International Journal of Advanced Manufacturing Technology. v. 51, n. 1-4, p. 15-24, mar. 2010.

Evaluation of alternative assembly line arrangements with stochastic operation times: A computer simulation approach. Journal of Manufacturing Technology Management. v. 23, n. 6, p. 806-822, 2012. 
A computer simulation approach to evaluating assembly line balancing with variable operation times. Journal of Manufacturing Technology Management. v. 21 , n. 7 , p. $872-887,2010$ a.

DAVIS, L. Pacing effects of manned assembly lines. International Journal of Production Research. v. 4, n. 3, 1966.

DUDLEY, N. Work-time distributions. International Journal of Production Research. v. 2, n. 2, p. 137-144, 1963.

EL-RAYAH, T. The efficiency of balanced and unbalanced production lines. International Journal of Production Research. v. 17, n. 1, p. 61-75, 1979.

FIGUEIRA, G.; ALMADA-LOBO, B. Hybrid simulation-optimization methods: A taxonomy and discussion. Simulation Modelling Practice and Theory. Elsevier B.V., v. 46, p. 118-134, ago. 2014.

HILLIER, F. S.; BOLING, R. W. The effect of some design factors on the efficiency of production lines with variable operation times. Journal of Industrial Engineering. v. 17, n. 12 , p. $651-658,1966$.

. Finite Queues in Series with Exponential or Erlang Service Times-A Numerical Approach. Operations Research. v. 15, n. 2, p. 286-303, 1967.

. On the Optimal Allocation of Work in Symmetrically Unbalanced Production Line Systems with Variable Operation Times. Management Science. v. 25, n. 8, p. 721-728, 1979.

HILLIER, F. S.; SO, K. C. Some data for applying the bowl phenomenon to large production line systems. International Journal of Production Research. v. 31, n. 4, p. 811-822, 1993.

On the robustness of the bowl phenomenon. European Journal Of Operational Research. v. 2217, n. 1979, p. 496-515, 1996.

HILLIER, M. Designing unpaced production lines to optimize throughput and work-in-process inventory. IIE Transactions. v. 45, n. 5, p. 516-527, maio 2013.

HILLIER, M.; HILLIER, F. S. Simultaneous optimization of work and buffer space in unpaced production lines with random processing times. IIE Transactions. v. 38, n. 1, p. 39-51, 2006.

HONG, Y. et al. Evaluation of mixed-model U-line operational designs. International Transactions in Operational Research. v. 20, n. 6, p. 917-936, jun. 2013.

HUNT, G. C. Sequential arrays of waiting lines. Operations Research. v. 4, p. 674-583, 1956.

KALA, R.; HITCHINGS, G. The effects of performance time variance on a balanced, four-station manual assembly line. International Journal of Production Research. v. 11, n. $2,1973$.

KARWAN, K.; PHILIPOOM, P. A note on "Stochastic unpaced line design: Review and further experimental results". Journal of Operations Management. v. 8, n. 1, p. 48-54, jan. 1989. 
KOTTAS, J. F.; LAU, H.S. Some problems with transient phenomena when simulating unpaced lines. Journal of Operations Management. v. 1, n. 3, p. 155-164, fev. 1981.

LAU, H.S. On balancing variances of station processing times in unpaced lines.

European Journal of Operational Research. v. 61, n. 3, p. 345-356, 1992.

LEE, C. et al. Organ doses for reference pediatric and adolescent patients undergoing computed tomography estimated by Monte Carlo simulation. Medical physics. v. 39, n. 4, p. 2129-2146, 2012.

LUDWIG, M.; HUEGE, T. REAS3: Monte Carlo simulations of radio emission from cosmic ray air showers using an "end-point"formalistm. Astroparticle Physics. v. 34, n. 6, p. $438-446,2011$.

MAHAJAN, P. S.; INGALLS, R. G. Evaluation of methods used to detect warm-up period in steady state simulation. In: Proceedings of the 2004 Winter Simulation Conference, 2004. p. 663-671.

MIRALLES, C. et al. Advantages of assembly lines in sheltered work centers for disabled: a case study. International Journal of Production Economics. v. 110, n. 1-2, p. 187-197, 2007.

MOREIRA, M. C. O.; MIRALlES, C.; COSTA, A. M. Model and heuristics for the Assembly Line Worker Integration and Balancing Problem. Computers \& Operations Research. v. 54, p. 64-73, 2015.

MORETTIN, P. A.; BUSSAB, W. d. O. Testes de hipóteses. In: Estatística básica, 2003. p. 323-355.

MUTH, E. J.; ALKAFF, A. The bowl phenomenon revisited. International Journal of Production Research. v. 25, n. 2, p. 161-173, 1987.

OTTO, A.; OTTO, C.; SCHOLL, A. Systematic data generation and test design for solution algorithms on the example of SALBPGen for assembly line balancing. European Journal of Operational Research. v. 228, n. 1, p. 33-45, jul. 2013.

PAPADOPOULOS, H. T.; HEAVEY, C. Queueing theory in manufacturing systems analysis and design: A classification of models for production and transfer lines.

European Journal of Operational Research. v. 92, n. 1, p. 1-27, 1996.

PATTERSON, R. Markov processes occurring in the theory of traffic flow through an N-Stage stochastic service system. Journal of Industrial Engineering. v. 15, n. 4, p. 188-193, 1964.

PAYNE, S.; SLACK, N.; R., W. A note on the operating characteristics of balanced and unbalanced production flow lines. International Journal of Production Research. v. 10, n. 1, 1972.

PIDD, M. Computer simulation in management science. 4th. ed. Chichester, UK: Wiley, 1998.

RAO, N. P. Two-Stage Production Systems with Intermediate Storage. IEE

Transactions. v. 7, n. 4, p. 414-421, 1975. 
. A generalization of the 'bowl phenomenon' in series production systems.

International Journal of Production Research. v. 14, n. 4, p. 437-443, 1976.

RAPP, D. Bubbles, Booms, and Busts: The Rise and Fall of Financial Assets. 2009. ed. [S.l.]: Copernicus, 2009. 274 p.

ROBINSON, S. Simulation : The Practice of Model Development and Use. [S.l.]: John Wiley \& Sons, Ltd, 2004.

SCHOLL, A. Balancing and Sequencing of Assembly Lines. 2. ed. [S.l.]: Physica, 1999. $318 \mathrm{p}$.

SHAABAN, S.; MCNAMARA, T.; ATIL, A. The behaviour of unpaced production lines with unequal mean processing times, variability, or buffer capacities. In: Proceedings for the Northeast Region Decision Sciences Institute. [S.l.: s.n.], 2011.

SMUNT, T.; PERKINS, W. Stochastic unpaced line design: A reply. Journal of Operations Management. v. 8, n. 1, p. 55-62, jan. 1989.

SMUNT, T. L.; PERKINS, W. C. Stochastic unpaced line design: Review and further experimental results. Journal of Operations Management. v. 5, n. 3, p. 351-373, maio 1985.

SO, K. C. On the efficiency of unbalancing production lines. International Journal of Production Research. v. 27, n. 4, p. 717-729, 1989.

SRIVASTAV, R. K.; SRINIVASAN, K.; SUDHEER, K. P. Simulation optimization framework for multi-season hybrid stochastic models. Journal of Hydrology. Elsevier B.V., v. 404, n. 3-4, p. 209-225, 2011.

TEKINER, H.; COLT, D. W.; FELDER, F. A. Multi-period multi-objective electricity generation expansion planning problem with Monte Carlo simulation. Electric Power Systems Research. v. 80, n. 12, p. 1394-1405, 2010.

TEMPELMEIER, H. Practical considerations in the optimization of flow production systems. International Journal of Production Research. v. 41, n. 1, p. 149-170, jan. 2003.

TEMPELMEIER, H.; BÜRGER, M. Performance evaluation of unbalanced flow lines with general distributed processing times, failures and imperfect production. IIE Transactions. v. 33, n. 4, p. 293-302, 2001. 
Apêndice 



\section{Decisões para implementação do modelo de simulação}

Este apêndice tem o objetivo de expor as tecnologias e decisões tomadas, do ponto de vista computacional, para a implementação do modelo de simulação desenvolvido neste trabalho (seção 4.2). A princípio, o conteúdo apresentado a seguir não afeta os resultados obtidos e as tecnologias utilizadas poderiam ser substituídas por outras ou mesmo implementadas totalmente. Também são feitos alguns comentários sobre as vantagens e desvantagens de se construir o próprio simulador em detrimento da utilização de um software comercial.

Todo o desenvolvimento foi feito utilizando-se a linguagem de programação Python 2.7.5 $+^{1}$, o plugin PyDev 3.2. $0^{2}$ para o ambiente de desenvolvimento integrado Eclipse 3.8.13 e sistema operacional Linux Ubuntu 12.10 . O simulador também foi testado nas versões 13.04 e 13.10 da distribuição Ubuntu do Linux. O simulador construído com essas tecnologias tem como entrada soluções dos modelos SALBP e ALWABP propostos (seção 4.1) obtidas utilizando a interface para Python do otimizador IBM ILOG CPLEX 12.5. $0^{5}$. Como mencionado, a escolha dessas tecnologias é de importância secundária para o desenvolvimento do trabalho e elas podem ser substituídas por outras de acordo com a necessidade/familiaridade do desenvolvedor.

Em termos de implementação existem três classes principais:

- Workstation: é a classe responsável por encapsular o comportamento interno de uma estação de trabalho. Os objetos dessa classe gerenciam as transições de estado apresentadas na Figura 10, além de, necessariamente, pertencerem a um objeto da classe AssemblyLine e serem capazes de distinguir qual a estação anterior e posterior

\footnotetext{
${ }^{1}$ Site oficial: python.org. Acessado em 18 de janeiro de 2014.

${ }^{2}$ Site oficial: pydev.org. Acessado em 18 de janeiro de 2014.

${ }^{3}$ Site oficial: eclipse.org. Acesado em 18 de janeiro de 2014.

${ }^{4}$ Site oficial: ubuntu.com. Acessado em 18 de janeiro de 2014.

${ }^{5}$ Site oficial: http://www-01.ibm.com/software/commerce/optimization/cplex-optimizer/. Acessado em 18 de janeiro de 2014.
} 
na linha de produção. Também, as tarefas a serem executadas e, se necessário, o trabalhador alocado à estação permitem a amostragem correta do tempo de processamento.

$\square$ AssemblyLine: é a classe responsável por controlar a lógica resumida na Figura 11. Um objeto desta classe possui como atributos o número de produtos produzidos até o momento em uma simulação, as estações que compõem a linha de produção, o tempo atual de simulação e uma fila com os eventos agendados para processamento.

Simulation: é uma classe de configuração de experimentos. Em outras palavras, ela é responsável pelo controle da realização dos experimentos, isto é, da linha de produção que será simulada, do número de vezes que ela será simulada e do número de produtos a serem produzidos em cada simulação. Também, é no interior desta classe que são salvos os resultados em arquivos com um formato pré-especificado para posterior análise.

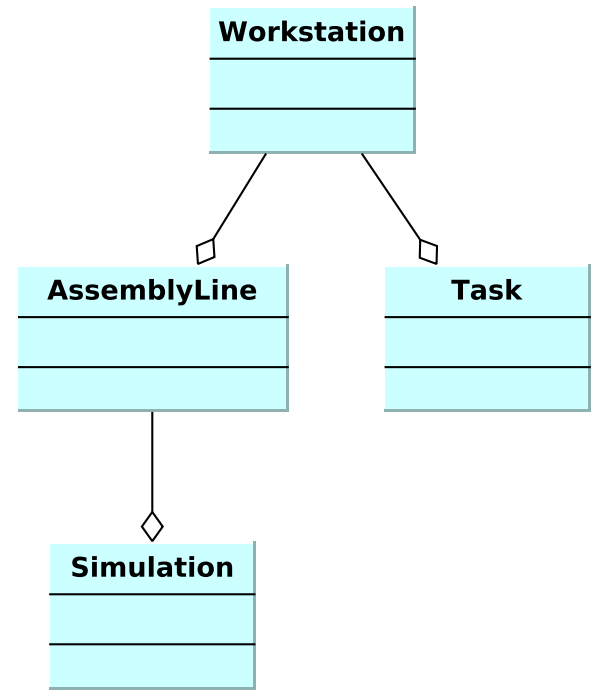

Figura 15 - Diagrama de classes simplificado do simulador, mostrando a relação entre as classes: Workstation, AssemblyLine, Simulation e Task.

Por fim, existe também a classe Task que é responsável pelo comportamento de uma tarefa, isto é, qual distribuição probabilística que rege aquela tarefa e seus parâmetros. A classe Task não está listada entre as principais pois trata-se de uma decisão de engenharia de software para facilitar a troca de distribuição probabilística das tarefas. Caso decida-se, por exemplo, utilizar a distribuição Exponencial não será necessário modificar o código do simulador, apenas adicionar algumas linhas de código na estrutura de controle adequada para incluir a possibilidade do uso da nova distribuição; não seria necessário, por exemplo, alterar códigos referentes a estruturas de controle das figuras 10 e 11, que são vitais para o funcionamento correto do simulador. A Figura 15 mostra a relação entre essas classes. 
Essas são as decisões mais expressivas, em termos de tecnologias utilizadas e engenharia de software, que permearam o desenvolvimento do simulador para linhas de produção não-ritmadas. Elas foram tomadas tendo como critério, principalmente, a facilidade de implementação, pois a construção do simulador é apenas um meio para possibilitar as análises do efeito Tigela considerando a integralidade das tarefas, que acredita-se ser a contribuição principal deste trabalho.

\section{Simulador próprio versus simulador comercial}

É sabido que existem diversos softwares de simulação no mercado como o ARENA $\AA{ }^{6}$ e o GoldSim ${ }^{7}$. No entanto, nesse trabalho, foi implementado um simulador próprio. Essa seção busca justificar a escolha dessa abordagem e deixar suas limitações claras para o leitor.

Os dois pontos primordiais a serem discutidos são: facilidade de uso e qualidade de resultados. Em relação à facilidade de uso, os softwares comerciais costumam possuir diversos recursos gráficos e do tipo drag-and-drop que podem auxiliar o usuário na construção do modelo desejado. No entanto, essa facilidade tem o custo de deixar a modificação dos modelos custosa. Por exemplo, na versão acadêmica do software GoldSim, um modelo de linha de produção precisaria ter todas estações e tarefas (distribuições probabilísticas e seus parâmetros) previamente configurados. Suponha, então, que seja preparado um experimento relativo ao desvio-padrão, com um determinado coeficiente de variação para cada estação. Para a realização de um outro experimento, para a mesma instância, mas com outro coeficiente de variação, todos os parâmetros de cada uma das tarefas do modelo teria que ser alterado manualmente. Deixando o trabalho de experimentação bastante custoso. Por outro lado, o simulador construído permite a automatização dessa tarefa por meio de scripts de programação. Na verdade, a principal desvantagem de um simulador construído, nesse aspecto, é a visualização de relatórios, pois um simulador comercial costuma possuir diversas opções de análise de resultados. Enquanto que o simulador construído realiza apenas um teste-t para garantir a diferença estatística entre duas amostras.

Em relação à qualidade de resultados, é importante se considerar a geração de números pseudo-aleatórios. Um simulador comercial costuma ter implementado diversos recursos estatísticos que garantem uma melhor aleatoriedade na geração de números pseudoaleatórios, o que aumenta a qualidade dos resultados, principalmente no que diz respeito à capacidade de generalização dos resultados. No entanto, para a geração de números pseudo-aleatórios foi utilizada o módulo random $^{8}$ do Python, que utiliza como núcleo de

\footnotetext{
${ }^{6}$ Site oficial do ARENA@: https://www.arenasimulation.com. Acessado em 22 de setembro de 2014.

${ }^{7}$ Site oficial do GoldSim: http://www.goldsim.com. Acessado em 22 de setembro de 2014.

${ }^{8}$ Manual do módulo: https://docs.python.org/2/library/random.html\#module-random. Acessado em 22 de setembro de 2014 .
} 
geração o algoritmo Mersenne Twister (um dos mais testados gerador de números aleatórios). Esse algoritmo possui um período de $2^{19937}-1$ : o suficiente para garantir a aleatoridade nos experimentos realizados.

Assim, apesar do custo de se implementar o próprio simulador, o que envolve conhecer tecnologias de programação e alguns detalhes de conceitos de simulação, para a aplicação nesse trabalho, o tempo economizado para realização nos testes de diversos cenários faz com que essa abordagem seja vantajosa. No entanto, é necessária uma análise caso a caso para verificar qual abordagem é mais eficiente garantindo a qualidade dos resultados. 